BNL- -52279

DE9 1011519

\title{
THE PHOENIX CONCEPT
}

\section{PROPOSED TRANSMUTATION OF LONG-LIVED RADIOACTIVE WASTES TO PRODUCE ELECTRIC POWER}

G.J. Van Tuyle, H. Takahashi, M. Todosow,

A.L. Aronson, G.C. Slovik and W.C. Horak

DEPARTMENT OF MUCLEAR ENERGY

BROOKHAVEN NATIONAL LABORATORY. ASSOCIATED UNIVERSITIES, INC. UPTON. NEW YORK 11973

Prepared for the

UNITED STATES DEPARTMENT OF ENERGY

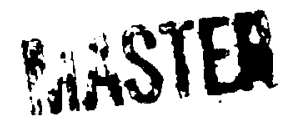




\begin{abstract}
A proposed means of transmuting key long-lived radioactive isotopes, primarily the socalled minor actinides ( $\mathrm{Np}, \mathrm{Am}, \mathrm{Cm}$ ), using a hybrid proton-accelerator-sub-critical lattice, is described. It is argued that by partitioning the components of the light water reactor (LWR) spent fuel and by transmuting key elements, such as the plutonium, the minor actinides, and a few of the long-lived fission products, that some of the most significant challenges in building a waste repository can be substantially reduced. If spent fuel partitioning and transmutation were fully implemented, the time required to reduce the waste stream toxicity below that of uranium ore would be reduced from more than 10,000 years to approximately 30 years. The proposed machine, based on the described PHOENIX Concept, would transmute the minor actinides and much of the iodine produced by $75 \mathrm{LWRs,}$ and would generate usable electricity (beyond that required to run the large accelerator) of $850 \mathrm{MW}$.
\end{abstract}




\section{EXECUTIVE SUMMARY}

The PHOENIX Concept uses a large linear proton accelerator to drive and control one or more subcritical lattices of minor actinides (Np, Am, Cm), to transmute the long-lived radioactive wastes from light-water reactors that are the most difficult to dispose of, and to produce electric power in the process. One $3600 \mathrm{MW}_{\mathrm{t}}$ machine would transmute the neptunium, americium, curium, and much of the iodine produced by about 75 light water reactors (LWRs), and would generate a net of about $850 \mathrm{MW}_{\mathrm{e}}$ for the electrical grid.

While not tied to a specific fuel reprocessing/recycling technology, much of the PHOENTX analysis performed thus far has been based on Westinghouse Hanford's proposed CURE approach, which is a waste partitioning process based on the well known PUREX process and the newer TRUEX process. Within the CURE framework, certain elements are to be recycled, transmuted, or simply separated from the major portion of the high-level wastes. The primary objective is to eliminate certain problem components from the bulk of the spent fuel so that the remainder can be packaged more easily (reduced heat load and shorter life-time requirements) for disposal in the geologic repository currently planned by DOE. In principle, the toxicity of the LWR waste stream could be reduced below that of naturally occurring uranium ore within a few decades ( $~ 30$ years), as opposed to more than 10,000 years if unprocessed. Of the key long-lived elements to be isolated, several, including the uranium, plutonium, and technetium, could be either recycled into current or future reactors, or packaged separately for burial in the repository. The elements that would be most difficult to consume in LWRs, namely the minor actinides and the iodine, could be transmuted in PHOENIX with a high degree of safety and efficiency. In particular, the safety advantage comes from always running the machine subcritical, thereby making reactivity accidents insignificant, and the efficiency advantage comes from eliminating the need for uranium or plutonium feed, because the accelerator can provide the necessary additional neutrons early in target lifetime.

The possible usage of hybrid accelerator - subcritical lattices for transmuting long-lived nuclear wastes is not new, but recent improvements in linear accelerator technology (SDI applications) and separation technology (Hanford) make this option more practical than was previously believed. Because the minor actinides will fission quite efficiently in a very hard (fast) neutronic spectrum, there are various options to consider, including sodium, lead, or helium coolants and oxide, metal, or other fuel forms. For PHOENIX, we have made specific assumptions regarding the design of the accelerator and the composition of the subcritical lattices. These assumptions are quite conservative regarding extensions of current technology, and the PHOENIX Concept described herein is considered credible.

The PHOENIX Concept assumes a large linear accelerator that can produce a $104 \mathrm{~mA}$ beam of $1.6 \mathrm{GeV}$ protons. While such an accelerator is an extension of the present technology, an even larger machine producing $250 \mathrm{~mA}$ of $1.6 \mathrm{GeV}$ protons was recently designed and independently evaluated by a DOE "ERAB" committee for usage in a concept for producing tritium. 
A multiple module (modular) concept was developed for the PHOENIX subcritical lattice. Each module resembles the core of the Fast Flux Test Facility (FFTF), with the minor actinides formed into oxide fuel rods, replacing the uranium and plutonium in the FFTF fuel. The choice of designing the target lattice to resemble FFTF was made largely to establish a creciible machine, with a well known design and substantial operational and materials performance data base. The fuel rods are cooled using liquid sodium, and are bundled into 217 pin assemblies, with 124 such assemblies making up a $450 \mathrm{MW}_{\mathrm{t}}$ target module. From 1 to 8 of these target modules are aligned in front of the proton beam, depending in part on how much of the "fuel" is available at any given time.

An alternate means of transmuting the minor actinides would be via reactors, most probably fast spectrum reactors since the minor actinides are strong absorbers of slow neutrons. There are various trade-offs involved in considering the two approaches, some of which involve predicting the future of nuclear energy usage in the U.S. By using an accelerator-driven system, one gains the ability to operate the system subcritical, which has various advantages including greater flexibility regarding fuel loading and in operating the system.

In contrasting the two approaches, the reactor approach might appear at first to be simpler. However, the physics taking place within the PHOENIX proton-driven lattice is not much more complex than that in a reactor. The number of fissions induced is directly proportional to the number of neutrons released via the spallation and evaporation processes as the proton passes into the lattice. This number of neutrons released is roughly 50 for each 1.6 $\mathrm{GeV}$ proton in a minor actinide lattice of the size of the PHOENIX target modules. The number of fissions then depends on the k-effective for the lattice. For a k-effective in the range of .9 to .95 , there will be far more fissions triggered (167 to 352 ) by a proton than there will be direct proton induced spallation (destruction) of actinide atoms (5 or 6). Therefore, the neutronic spectrum and the resultant fission products would be quite similar to those in a comparable reactor, and the PHOENIX target design would be based almost exclusively on current or planned advanced liquid-metal-cooled reactor technology.

In terms of capital cost, one PHOENIX unit should cost roughly 1.5 times as much as a liquid- metal-cooled reactor of comparable rating $(3600 \mathrm{MW})$. However, the throughput of minor actinides (not to mention the iodine) would be much higher for PHOENIX, as there is no uranium or plutonium contributing to the heat production or leading to the creation of more minor actinides.

The use of 1 PHOENIX unit starting in the year 2000 would cut the growth in the minor actinide inventory by $75 \%$. If.a second unit starts up in the year 2010 , all the back-log of minor actinides would be consumed by the early 2040s. (It is noted that the current average capacity factors for U.S. LWRs are so low (roughly 65\%) that 1 PHOENIX unit could process almost all of the current production of minor actinides.)

We consider the PHOENIX Concept to be credible as a large scale actinide burner for transmuting nuclear wastes. The next step is to determine whether such a machine is feasible from an engineering standpoint, i.e., can such a machine be built and operated. In some instances this may involve consideration of trade-offs of various options, such as the structural 
materials to be used in the target. A list of the major areas to be evaluated as part of an engineering feasibility study follows:

1. Because an accelerator designed to deliver a $250 \mathrm{~mA}$ current of $1.6 \mathrm{GeV}$.has already been independently evaluated by a DOE ERAB Committee, we are adopting a down-sized version of that machine as our reference design. During this study we would evaluate cost savings that would result from eliminating the "funneling" aspect of the $250 \mathrm{~mA}$ design, and consider whether other types of accelerators might warrant consideration.

2. BNL has an operational two-dimensional beam expander system, upon which the larger beam expander required for PHOENIX would be based. The distribution of protons in both dimensions are quite similar to the proton distributions that were predicted analytically, and we believe that this system can be scaled up without major difficulties. As part of this study we would perform the necessary design calculations, and consider issues such as possible expander system failure modes and possible materials damage in the large scale system.

3. The major focus of the feasibility study will be the target system. Even though the current target design is based on the FFTF reactor, there are some key differences that must be considered. These differences include a somewhat harder neutronic spectrum, due to the neutrons created via spallation and evaporation, as well as the use of $\mathrm{Am}, \mathrm{Np}$, and $\mathrm{Cm}$ rather than $\mathrm{U}$ and Pu. Also, the PHOENIX target modules will be designed for high leakage of neutrons and large burnup reactivity swings. Finally, the high energy protons will add to the materials damage, although the predominance of neutron-induced fissions suggests that the materials behavior in FFTF should provide an excellent first guess regarding materials damage. Target system efforts would include the following:

a. Using Monte-Carlo codes (HETC/NMTC and MCNP) and Neutron Transport Codes (ANISN) to perform multi-dimensional analyses of the processes taking place in the target lattices. This would entail determining three-dimensional neutron, proton, and power distributions, the neutron muitiplication factor (k-effective), and key reactivity feedbacks including, Doppler and sodium void worth.

b. The target dimensions must be optimized to give the desired neutron leakage. Further, the anticipated increase in reactivity must be compensated for, and some combination of poison rods and geometry changes must be planned.

c. In principle, a metal fuel form would provide a harder neutronic spectrum than that in an oxide fuel lattice and could provide improved machine efficiencies and reduced burnup reactivity swings. During the proposed study, we plan to perform calculations sufficient to quantify the potential advantages from using metal fuel. In addition, alternate coolant options would be evaluated. 
d. Neutronic data bases are required to predict target performance and how that performance will change with burnup. BNL's cross section libraries are state-of-the art, but the data for the minor actinides in a fast neutronic spectrum may not be as complete as one would like. This situation will have to be evaluated.

e. While extrapolation from materials testing at FFTF should provide good initial estimates of the materials damage to be expected in the PHOENIX target, tests using $1.6 \mathrm{GeV}$ protons should be planned. We can access a beam of $1.6 \mathrm{GeV}$ protons from BNL's Alternating Gradient Synchrotron (AGS) Booster and, by focusing on a few square centimeters of surface area, replicate the proton beam intensity expected at the front face of the PHOENIX Target Modules.

4. Hanford (Brager, et al, ANS Transactions, Volume 62) has recently proposed an iodine target based on $\mathrm{Ce}_{3}$ with HT-9 cladding. This fission product target design will be evaluated for use in the PHOENIX concept. Fission product target configurations will be considered, and estimates will be made regarding the rate at which I-129 can be transmute: to stable xenon isotopes.

At the end of the proposed study, we would expect to have a viable target design, estimates of the iodine throughput and materials damage, and a conceptual design for both the accelerator and beam expansion systems. 


\section{ACKNOWLEDGEMENTS}

Several individuals have provided important input and feedback regarding the proposed PHOENIX Concept, and it would be impossible to acknowledge every significant contribution. Among those at BNL providing important input were Drs. S. Baron, J. Guppy, W. Kato, M. Steinberg, T. Ward, and J. Weeks. The expertise of these individuals spans a gamut from reactor safety to accelerator physics and from materials sciences to process technology, and their advisement regarding the proposed technology was essential. Several individuals outside BNL were also consulted, with the most significant contributions coming from a group at the Westinghouse Hanford Corporation working on the CURE process and exploring various waste transmutation options themselves. The input we received from Drs. John Rawlins and Fred Mann were especially helpful.

Very helpful editorial feedback was provided by Drs. R. Bari, J. Guppy, W. Kato, and others. The typing and processing of this report were performed by Mrs. Kathy Ratto and Mrs. Linda Hanlon. The several iterations of this report were managed with great patience and skill. 


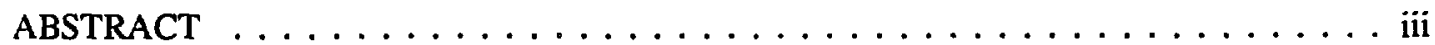

EXECUTIVE SUMMARY $\ldots \ldots \ldots \ldots \ldots \ldots \ldots \ldots$

ACKNOWLEDGEMENTS $\ldots \ldots \ldots \ldots \ldots \ldots \ldots \ldots \ldots \ldots$ ix

LIST OF FIGURES $\ldots \ldots \ldots \ldots \ldots \ldots \ldots \ldots \ldots \ldots \ldots \ldots \ldots \ldots \ldots \ldots$

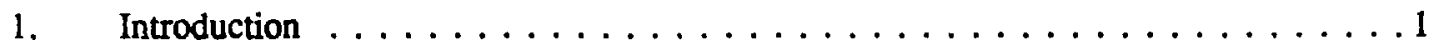

2. Radioactive Wastes and CURE $\ldots \ldots \ldots \ldots \ldots \ldots \ldots \ldots$

2.1 Status of Spent Fuel and Wastes $\ldots \ldots \ldots \ldots \ldots \ldots \ldots$

2.2 Toxicity Reduction Using CURE Processing (Ref. 1) $\ldots \ldots \ldots \ldots$.

2.3 Key Elements and Isotopes $\ldots \ldots \ldots \ldots \ldots \ldots \ldots \ldots \ldots$

2.4 The Cure Process (Ref. 1) $\ldots \ldots \ldots \ldots \ldots \ldots \ldots \ldots \ldots$

2.5 Other Current Perspectives on Waste Processing $\ldots \ldots \ldots \ldots \ldots$

3. The PHOENIX Concept $\ldots \ldots \ldots \ldots \ldots \ldots \ldots \ldots \ldots \ldots$

3.1 Characteristics of the Minor Actinides $\ldots \ldots \ldots \ldots \ldots \ldots$

3.2 Spallation and Neutronics $\ldots \ldots \ldots \ldots \ldots \ldots \ldots$

3.3 Fission-Product Targets $\ldots \ldots \ldots \ldots \ldots \ldots \ldots \ldots \ldots$

4. PHOENIX Design Studies . . . . . . . . . . . . . . . . . . . . . 29

$4.1 \quad$ Lattice Types . . . . . . . . . . . . . . . . . . . . . . . . 29

4.2 Sizing and Design Calculations for Target Modules and Lattice . . . . . 31

4.3 Burn-Up Calculations $\ldots \ldots \ldots \ldots \ldots \ldots \ldots \ldots \ldots \ldots \ldots$

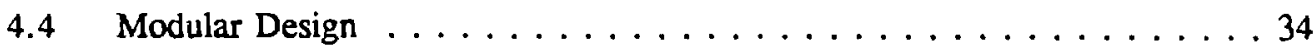

4.5 Accelerator Performance at Reduced Loadings $\ldots \ldots \ldots \ldots \ldots$ 
TABLE OF CONTENTS (CONT'D)

Page

5. Impact of PHOENIX on Actinide Inventories $\ldots \ldots \ldots \ldots \ldots \ldots \ldots$

6. Engineering Feasibility Study $\ldots \ldots \ldots \ldots \ldots \ldots \ldots \ldots \ldots \ldots \ldots$

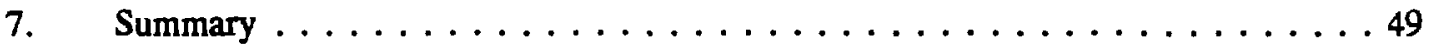

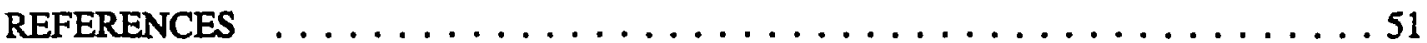




\section{LIST OF FIGURES}

Figure No.

Page

The PHOENIX Concept $\ldots \ldots \ldots \ldots \ldots \ldots \ldots \ldots$

Transmutation of Minor Actinides:

Accelerator-Subcritical Hybrids vs. Reactors $\ldots \ldots \ldots \ldots \ldots 4$

Conversion Ratio-Protons to Transmutations $\ldots \ldots \ldots \ldots \ldots$

U.S. LWR Waste Component Masses $\ldots \ldots \ldots \ldots \ldots \ldots$

Impact of Partial Waste Processing $\ldots \ldots \ldots \ldots \ldots \ldots$

Half-Life and Activity of TRU Waste Isotopes

from $1 \mathrm{GW}$ Electricity - After 10 Years of Decay ......... 11

Characteristics of Key LWR Fission Products $\ldots \ldots \ldots \ldots 12$

Components of the CURE Process $\ldots \ldots \ldots \ldots \ldots \ldots$

Cure Process Flow Schematic $\ldots \ldots \ldots \ldots \ldots \ldots \ldots$

Minor Actinides Generated per year in a $3410 \mathrm{MW}_{\mathrm{t}} \mathrm{LWR} \ldots \ldots 18$

Thermal Cross Sections for Key Actinides . . . . . . . . . . 19

Heavy-Metal Isotope Buildup/Decay Chain $\ldots \ldots \ldots \ldots . . .20$

Fast Cross Sections for Key Actinides (1 to $20 \mathrm{MeV}$ ) . . . . . 21

Comparison of Neutron Spectra $\ldots \ldots \ldots \ldots \ldots \ldots . \ldots 22$

High Energy Proton - Induced Nuclear Spallation Reaction . . . . 24

Number of Nuclide Spallated per an Incident Proton Energy . . . . 25

Number of Neutrons Produced per an Incident Proton Energy . . . . 26

Iodine and Technetium Chains $\ldots \ldots \ldots \ldots \ldots . \ldots 27$

PHOENIX Lattice Fuel Pins Are Currently

Based on FFTF Oxide Fuel $\ldots \ldots \ldots \ldots \ldots \ldots$ 


\section{LIST OF FIGURES (CONT'D)}

Figure No.

$250 \mathrm{~mA}$ Accelerator with PHOENIX Beam Expander and

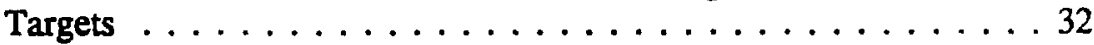

PHOENIX Transmutes the Wastes That Cannot Go Into

Thermal Reactors . . . . . . . . . . . . . . . . . 33

22

Reactivity Increase and Mass of Principal Actinides

During First 12 Years of Bum-Up in $3600 \mathrm{MW}$. PHOENIX

Lattice, Assuming Plutonium is Removed During

Reprocessing ....................... . . . . . . . . . . .

Mass of Key Isotopes During First 12 Years of Burn-Up in $3600 \mathrm{MW}$, PHOENIX Iattice, Assuming Pu and U Removed During Reprocessing . . . . . . . . . . . . . . . . . 36

$450 \mathrm{MW}_{\mathrm{t}}$ Sub-Critical Module . . . . . . . . . . . . 38

PHOENIX Modular Lattice Concapt . . . . . . . . . . . . . . 39

PHOENIX Target Chamber From Three Perspectives . . . . . . . . 40

Power Requirements, Beam Current, and Effective

Multiplier $\mathrm{k}$ as Function of Duty Factor for $104 \mathrm{~mA}$

LINAC with $3600 \mathrm{MW}_{\mathrm{t}}$ Lattice ... . . . . . . . . . . . . 41

Power Production and Utilization (Accelerator and Grid)

As a Function of Number of Target Modules On-Line

Impact of PHOENIX on Minor Actinide Inventory if Continue 


\section{INTRODUCTION}

The PHOENIX Concept uses a large linear proton accelerator to drive and control one or more subcritical lattices of minor actinides (Np, Am, Cm), to transmute the long-lived radioactive wastes from light-water reactors that are the most difficult to dispose of, and to produce electric power in the process. One $3600 \mathrm{MW}_{\mathrm{t}}$ machine would transmute the neptunium, americium, curium, and much of the iodine produced by about 75 light water reactors (LWRs), and would generate a net of about $850 \mathrm{MW}_{\mathrm{e}}$ for the electrical grid, as indicated in Figure 1.

While not tied to a specific fuel reprocessing/recycling technology, much of the PHOENIX analysis performed thus far has been based on the proposed CURE approach (Ref. 1), which is a waste partitioning process based on the well known PUREX process and the newer TRUEX process. Within the CURE framework, certain elements are to be recycled, transmuted, or simply separated from the major portion of the high-level wastes. The primary objective is to eliminate certain problem components from the bulk of the spent fuel so that the remainder can be packaged more easily (reduced heat load and shorter life-time requirements) for disposal in the geologic repository surrently planned by DOE. In principle, the toxicity of the LWR waste stream could be reduced below that of naturally occurring uranium ore within a few decades, as opposed to more than 10,000 years if unprocessed. Of the key long-lived elements to be isolated, several, including the uranium, plutonium, and technetium, could be either recycled into current or future reactors, or packaged separately for burial in the repository. The elements that would be most difficult to consume in LWRs, namely the minor actinides and the iodine, could be transmuted in PHOENIX with a high degree of safety and efficiency.

The possible usa:" of hybrid accelerator - subcritical lattices for transmuting long-lived nuclear wastes has been discussed previously (Ref. 2 and 3). Because the minor actinides will fission quite efficiently in a very hard (fast) neutronic spectrum, there are various options to consider, including sodium, lead, or helium coolants and metal, oxide, or other fuel forms. For PHOENIX, we have made specific assumptions regarding the design of the accelerator and the composition of the subcritical lattices. These assumptions are quite modest regarding extensions of current technology, and the PHOENIX Concept described herein is considered credible.

The PHOENIX Concept assumes a large linear accelerator that can produce a $104 \mathrm{~mA}$ beam of $1.6 \mathrm{GeV}$ protons. While such an accelerator is an extension of the present technology, an even larger machine producing $250 \mathrm{~mA}$ of $1.6 \mathrm{GeV}$ protons was recently designed and evaluated for usage in a concept for producing tritium (Refs. 4 and 5).

A multiple module (modular) concept was developed for the PHOFNIX subcritical lattice. Each module resembles the core of the Fast Flux Test Facility (FFTF) (Rer. 6), with the minor actinides formed into oxide fuel rods, replacing the uranium and plutonium in the FFTF fuel. The fuel rods are cooled using liquid sodiem, and are bundled into 217 pin assemblies, with 124 such assemblies making up a $450 \mathrm{MW}_{\mathrm{t}}$ target module. From 1 to 8 of these target modules are aligned in front of the proton beam, depending in part on how much of the "fuel" is available at any given time. 
Figure 1. The PHOENIX Concept

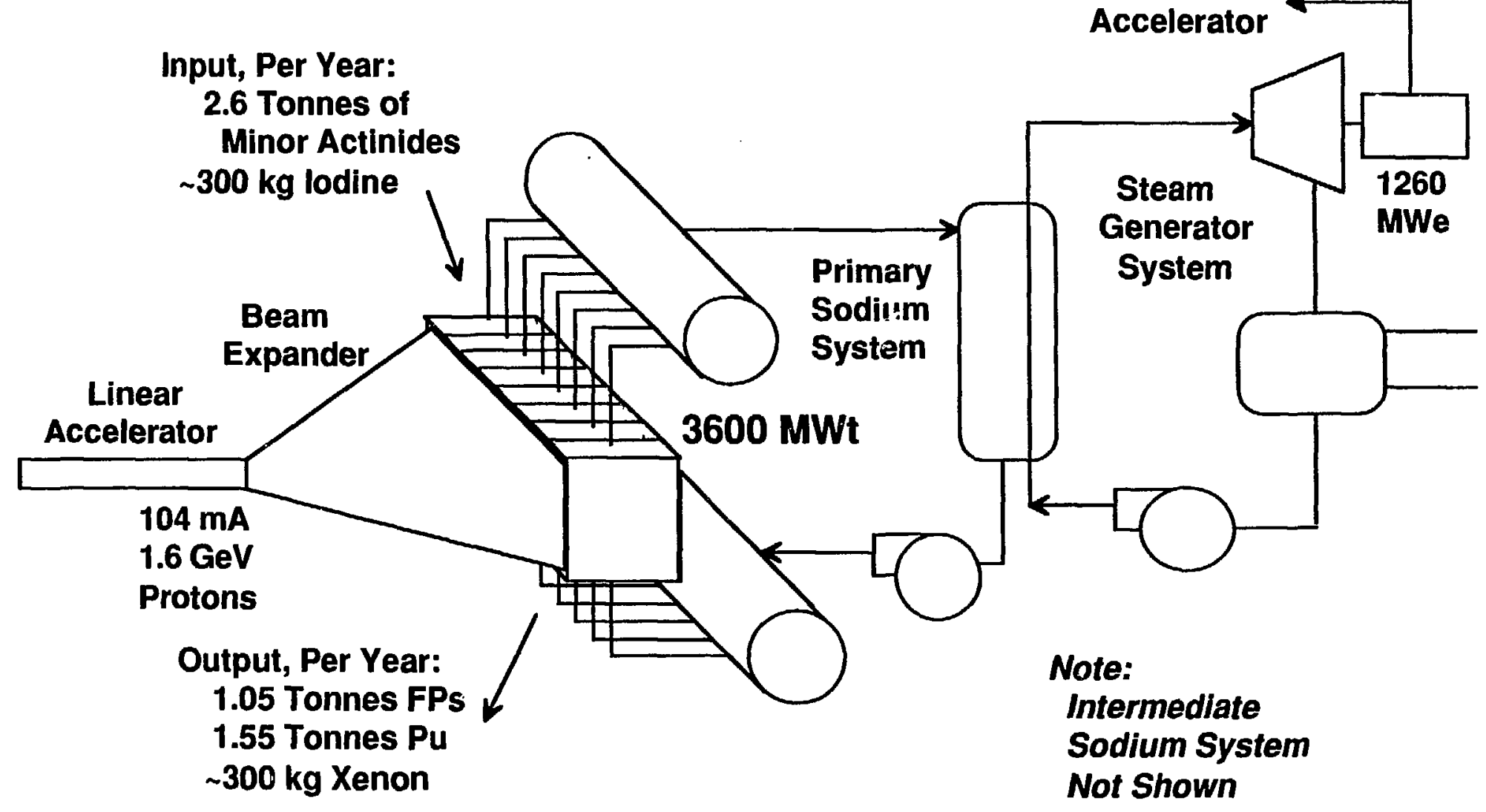


An alternative means of transmuting the minor actinides would be via reactors, most probably fast spectrum reactors since the minor actinides are strong absorbers of slow neutrons. Some of the relative advantages and disadvantages of each approach are listed in Figure 2. With the designs still undergoing revisions and improvements it may be premature to make any judgements regarding which is the preferred option for waste transmutation. However, we believe some of the potential advantages offered by the accelerator-driven system are significant enough to warrant closer examination of this option.

In contrasting the two appros thes, the reactor approach might appear at first to be simpler. However, the physics taking place within the PHOENIX proton-driven lattice is not much more complex than that in a reactor, as illustrated in Figure 3 . The number of fissions induced is directly proportional to the number of neutrons released via the spallation and evaporation processes as the proton passes into the lattice. This number of neutrons released is roughly 50 for each $1.6 \mathrm{GeV}$ proton in a minor actinide lattice of the size of the PHOENIX target modules. The number of fissions then depends on the k-effective for the lattice. Note that for a $k$-effective in the range of .9 to .95 , there will be far more fissions triggered (167 to 352) by a proton than there will be direct proton induced spallation (destruction) of actinide atoms (5 or 6). Therefore, the neutronic spectrum and the resultant fission products would be quite similar to those in a comparable reactor, and PHOENIX target design would be based almost exclusively on current or planned advanced liquid-metal-cooled reactor technology.

In terms of capital cost, one PHOENIX unit should cost roughly 1.5 times as much as a liquid- metal-cooled reactor of comparable rating $\left(3600 \mathrm{MW}_{\mathrm{t}}\right)$. However, the throughput of minor actinides (not to mention the iodine) would be much higher for PHOENIX, as there is no uranium or plutonium contributing to the heat production or leading to the creation of more minor actinides.

Key findings from the CURE report (Ref. 1) will be summarized in Section 2, and key physics aspects for the PHOENIX Concept, focusing primarily on the targets, will be discussed in Section 3. The current PHOENIX Concept design is discussed in Section 4, which includes the results from a 12 year "burnup" calculation. The potential impact of one or two PHOENIX machines on the United States inventory of minor actinides over the next sixty years is discussed in Section 5. Lastly, a prcposed engineering feasibility study is discussed briefly in Section 6. 
Figure 2. Transmutation of Minor Actinides: Accelerator-Subcritical Hybrids vs. Reactors

$\frac{\text { Issue }}{\text { Subcriticality }}$
Reactivity Build-Up
Shut-Down
Reactivity Accidents
Uncertainties in
Cross Sections
Problem Fission
Products from
LWR Waste Stream

\section{Accelerator-Subcritical Lattice}

Supplement Using Accelerator

(Protons Induce Spallation)

\section{Reduce Current \\ Adjust "Burnup" Rods \\ Change Geometry}

$+\quad$ Shut-Down

Reactivity Accidents

Insignificant: Subcritical

Adjust Beam to Compensate

Transmute Using Leaked

Neutrons or Additional Targets

(2)
Reactor (Fast Spectrum)

Add Fissile Materials

(More Actinides \& Fission Products)

Burn-Off Fissile Loading ( $\mathrm{U}$ or $\mathrm{Pu}$ )

Adjust "Burnup" Rods

Reduce Fuel Loading

Scram Systems

"Passive" Shutdown Systems (1)

Scram or "Passive" Shutdown (1)

Perform Critical Experiments

Not Addressed

(Need Thermal Neutrons)

Notes:

1) Passive Shutdown Available for Certain Reactor Designs and May Have Limitations

2) Accelerator Current Available to Drive Alternate Targets During Later Portions of Burnup Cycles 


\section{Figure 3. Conversion Ratio-Protons to Transmutations}

Number of Transmutations $=$ Number of Fissions + Number of Spallations (Proton Induced Fissions)

Number of Neutrons $=$ Number of Source Neutrons $\times(1+k+k \times k+k \times k \times k+\ldots)$,

where: Number of Source Neutrons $=$ Number from Spallation + Number from Evaporation

$k=k$, effective $=$ Effective Neutron Multiplication Factor for the Lattice

Therefore: Number of Neutrons $=$ Number of Source Neutrons $\times(1 /(1-k)) \quad$ (Geometric Series)

Number of Fission Neutrons $=$ Number of Neutrons - Number of Source Neutrons

$$
=\text { Number of Source Neutrons } x(k /(1-k))
$$

Number of Fissions $=$ Number of Fission Neutrons $/ v$,

where: $\quad v=$ Number of Neutrons Released per Fission

Therefore: Number of Fissions $=$ Number of Source Neutrons $\times(k /(1-k)) / v$

Number of Transmutations $=$ Number of Source Neutrons $\times(k /(1-k)) / v+$ Number of Spallations

Assuming: 5 Proton Induced Fissions, 50 Source Neutrons, 2.7 Neutrons per Fission:

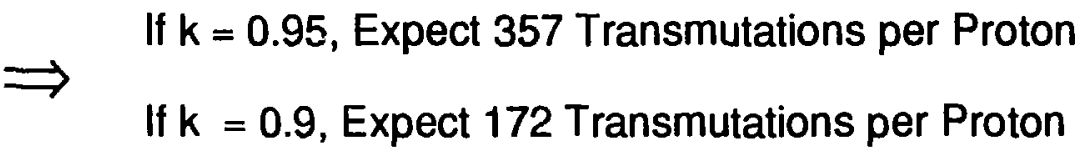




\section{RADIOACTIVE WASTES AND CURE}

\subsection{Status of Spent Fuel and Wastes}

The scope of the nuclear waste problem in the U.S. is illustrated in Figure 4, with projected masses shown for the years 1995 and 2020. A once-through fuel cycle means disposal of the large quantity in the left-hand portion of the figure. If the wastes were separated, the plutonium, actinides, and long-lived fission products also shown in the figure would be the most important factors, as these are the materials that are most difficult to dispose of safely.

\subsection{Toxicicy Reduction Using CURE Processing (Ref. 1)}

A major objective of the CURE process is to reduce the toxicity of the waste stream, as illustrated in Figure 5. The ingestion toxicity (how much water is required to dilute the material to reach safe drinking water standards) for different waste stream scenarios are compared against that of natural uranium, a reasonable standard since, for values less than 1 , the waste is returned to the earth less toxic than when it was first removed. The top curve shows the toxicity of the entire waste stream, assuming a once-through fuel cycle. Even after 10,000 years, this waste stream remc 's two or three times more toxic than natural uranium. If the plutonium and uranium are separated, resulting in a second curve, the toxicity falls off significantly after 1000 years. Although it is not shown in Figure 5, the toxicity from the plutonium is 4 to 5 orders of magnitude greater than that of the uranium. The additional removal of the minor actinides, i.e., neptunium, americium, and curium from the waste stream results in a third toxicity curve. Note here that the waste stream reaches the equal-toxicity point after 3 or 4 centuries. Of the remaining waste stream, four isotopes stand out as problems: Sr-90, Cs-137, Tc-99, and I-129. The first two have half-lives of around 30 years and contribute significantly to the short-term radioactivity and heat load (a packaging problem). The latter two have very long half-lives, as well as high mobility and, thus, are problems when considering water intrusion and leaking. If these four key isotopes are removed from the waste stream (in addition to the actinides), the lowest toxicity curve results. The resulting waste stream would reach equal-toxicity within a few decades (i.e., $\sim 30$ years).

While relative toxicity is one measure of the hazards posed by the long-lived waste, another key measurement is risk - which factors in the likelihood of the material escaping to the environment. Because key fission products, especially the iodine and technetium, are far more likely to leach into the environment one must also address these fission products in order to significantly reduce the repository risks (Refs. 7,8 ).

\subsection{Key Elements and Isotopes}

Of the uranium remaining in the spent fuel after 10 years of storage (the CURE assumption), only $0.8 \%$ is fissionable (U-235). While this uranium could be recycled into power reactors, some enrichment (or supplementing with plutonium) would be required before it could be used in light-water reactors (LWRs). 
Figure 4. U.S. LWR Waste Component Masses

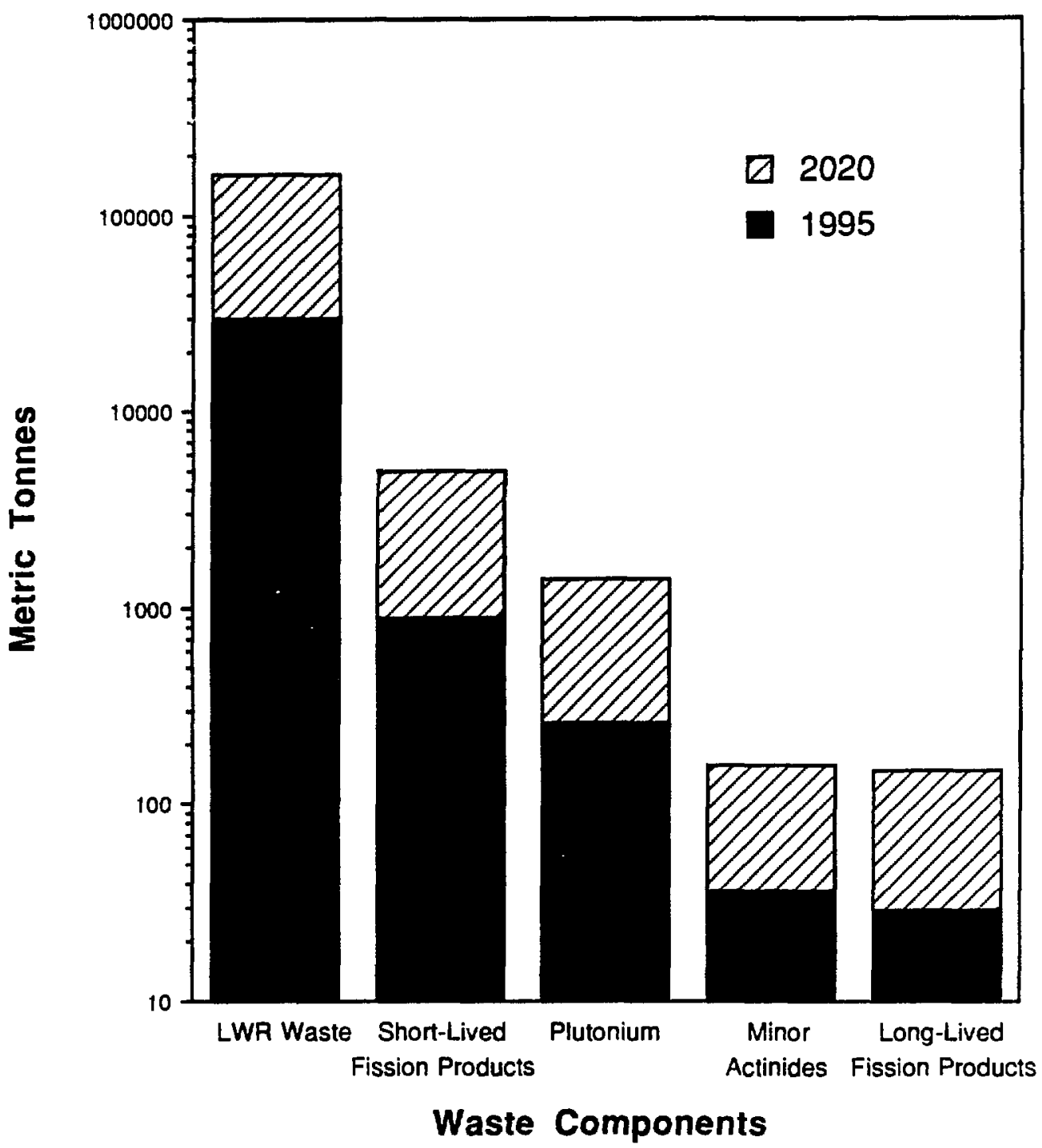


Figure 5. Impact of Partial Waste Processing

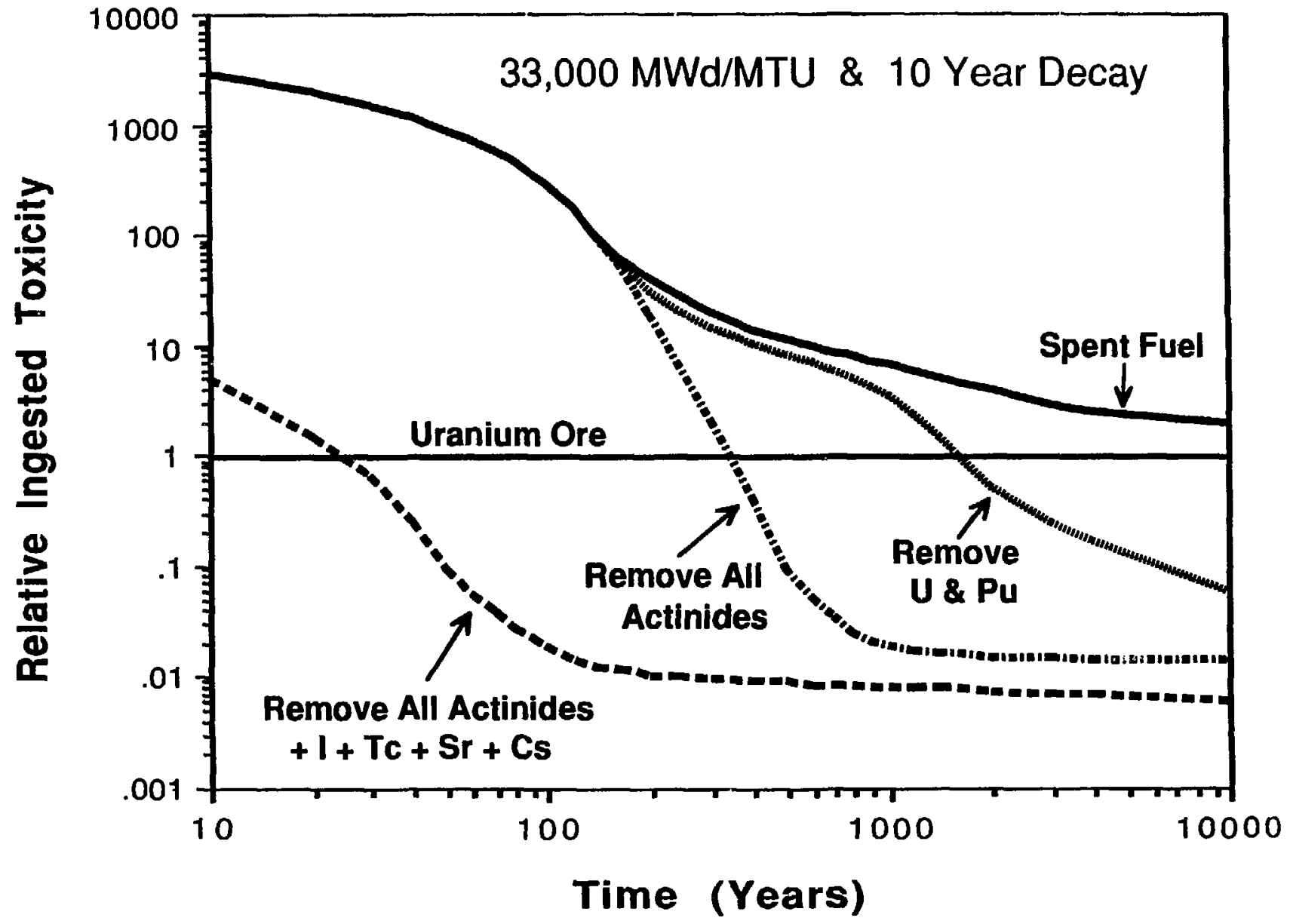


Fully two thirds of the plutonium is fissionable $\mathrm{Pu}-239$ and $\mathrm{Pu}-241$, and in contrast to uranium, plutonium is highly toxic. Because of the quantity of plutonium involved and the relatively high fissile content, the LWR waste plutonium may be better classified as a fuel, as opposed to a waste to be consumed (assuming that it is to be consumed at all).

The remaining actinides, often referred to as the "minor actinides", include neptunium, americium, and curium. Half-lives and activities of these actinides are shown in Figure 6. Several of these isotopes have long half-lives, and others have relatively high activities. Very few of these isotopes fission thermally, and most of them absorb thermal neutrons effectively. After absorbing two neutrons, on average, they eventually evolve into fissionable isotopes. (Note: in a very high thermal neutron flux, it is possible to fission a short-lived fissile isotope before it decays, which could reduce the number of neutrons absorbed from two to one.) However, these minor actinides would initially be strong poisons if placed into LWRs.

Of the many fission products, only a few have sufficiently long half-lives to cause problems for burial. Seven such fission products are shown in Figure 7. The Sr-90 and Cs-137 are problems over the near term, i.e., a few hundred years, as they are highly active and contribute significantly to both toxicity and heat loading. The other five isotopes in Figure 7 are approximately equivalent when judged by half-lives and toxicity. However, the Tc-99 and I-129 are much more mobile and thus more likely to leach into the ground water. Therefore, it is these four fission products, Sr-90, Cs-137, Tc-99, and I-129 that are the highest priority for elimination.

\subsection{The Cure Process (Ref. 1)}

This section summarizes the important features of the CURE process necessary to understand the PHOENIX Concept. Reference 1 contains a complete description of the CURE process and its various options.

The CURE proposal illustrated in Figure 8 and 9 comprises three primary functions:

- Reprocessing of spent LWR fuel to recover and recycle the uranium and plutonium.

- Partitioning of key long-lived actinides and fission products Tc-99 and radioiodine from either the high level waste (HLW) or certain off gases generated in the reprocessing of spent LWR and fast reactor fuels. As necessary or desirable, radiostrontium and radiocesium will also be partitioned from the HLW.

- Transmutation, in suitable nuclear facilities, of the recovered and purified actinide elements and Tc-99 and radioiodine to stable isotopes, short-lived radioactive products, or potentially valuable by-product (e.g., Pu-238). When partitioned from the HLW, radiostrontium and radiocesium would be safely disposed of in a deep geologic repository or in near-surface engineered facilities either before or after beneficial use or possibly transmuted to nonhazardous products in an advanced nuclear facility. 
Figure 6. Half-Life and Activity of TRU Waste Isotopes from $1 \mathrm{GWd}$ of Energy Production, After 10 Years of Decay

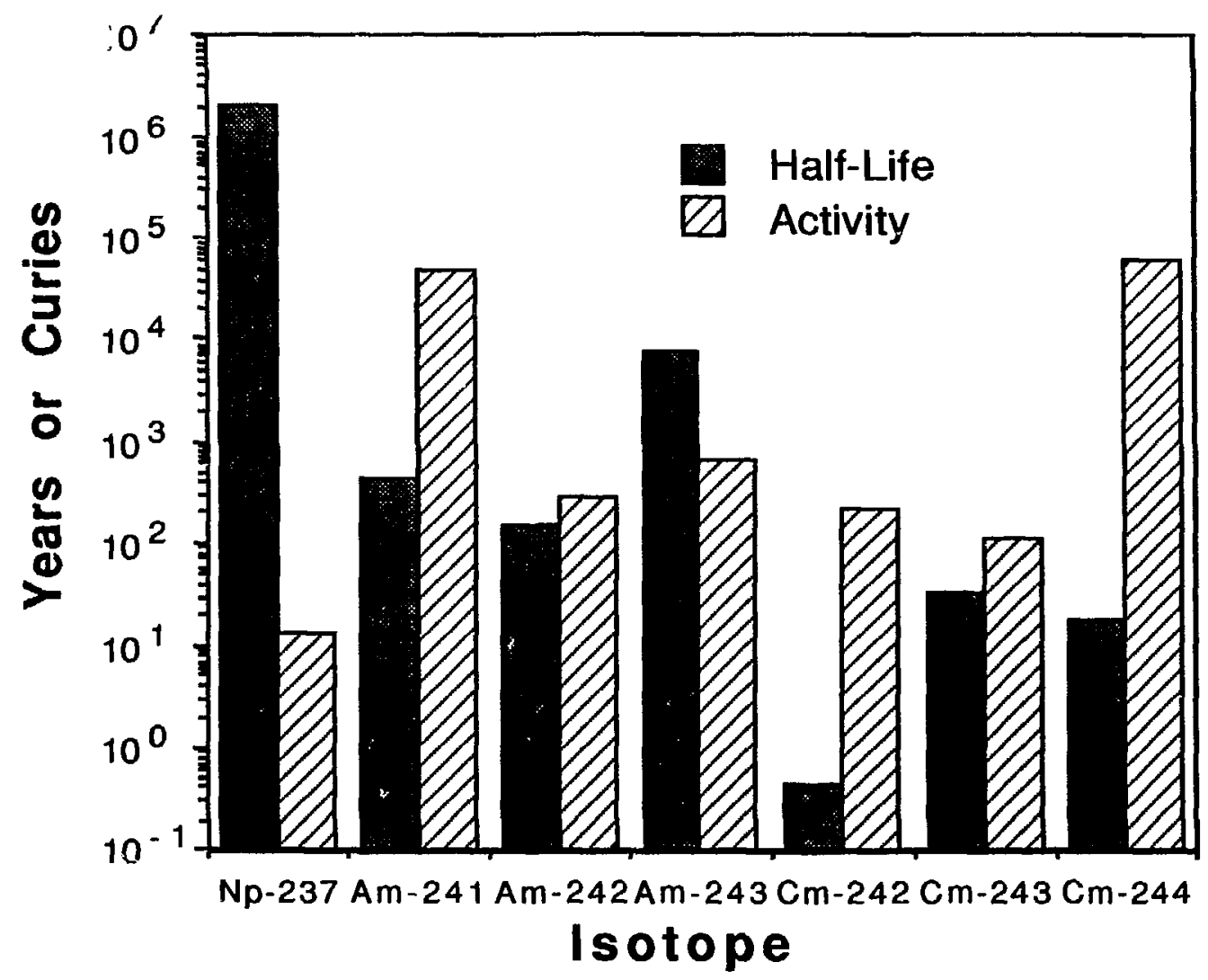


Figure 7. Characterisitics of Key LWR Fission Products

(At least 100g/MTU and Half-Life Longer than $100 \mathrm{yrs}$, or Toxicity Greater Than 100 Million Cubic Meters of Water)

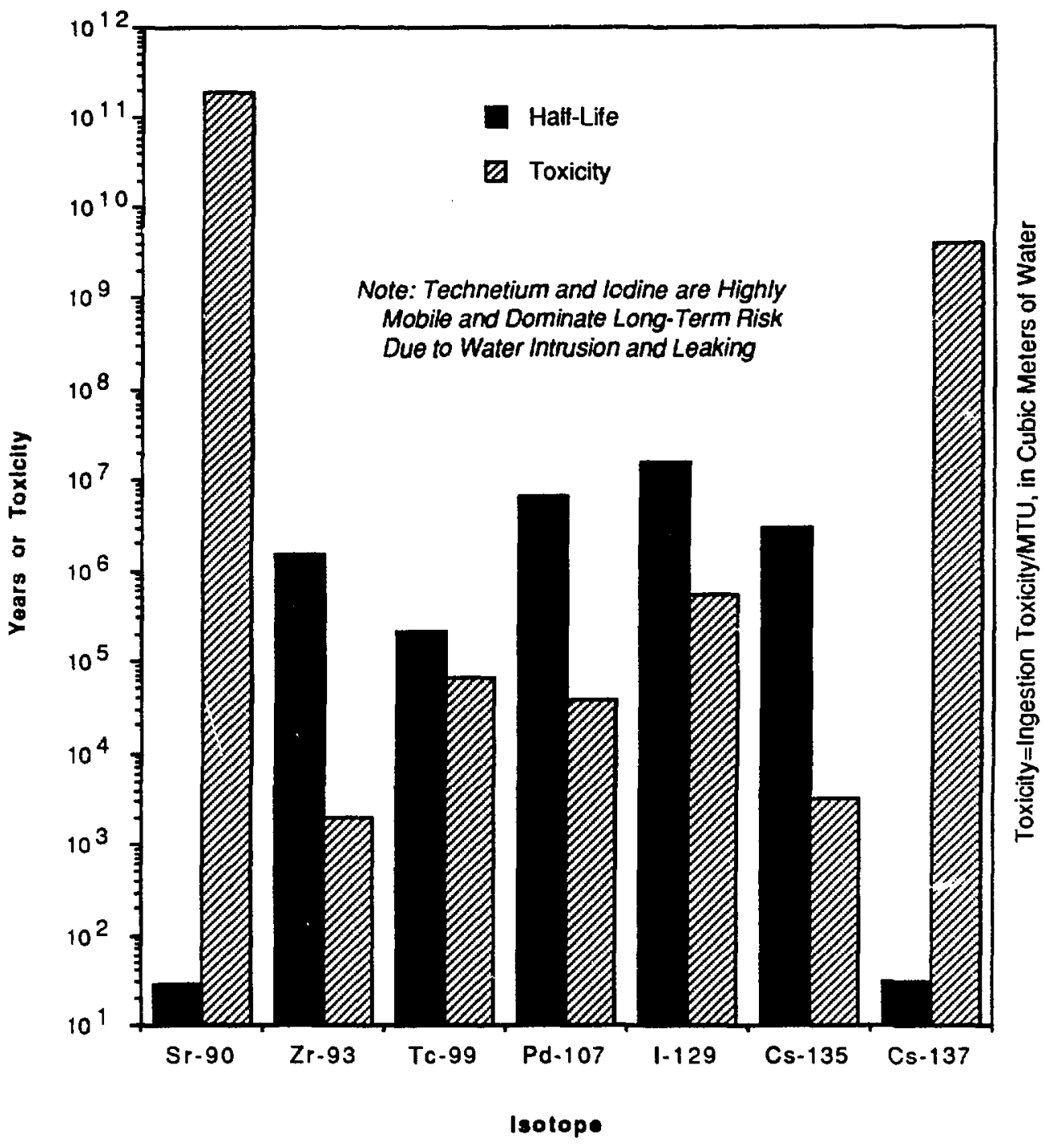

Toxicity=Volume of Pure Water Required to Dilute the Element or Isotope to Drinking Water Standards 


\section{Figure 8. Components Of The CURE Process}

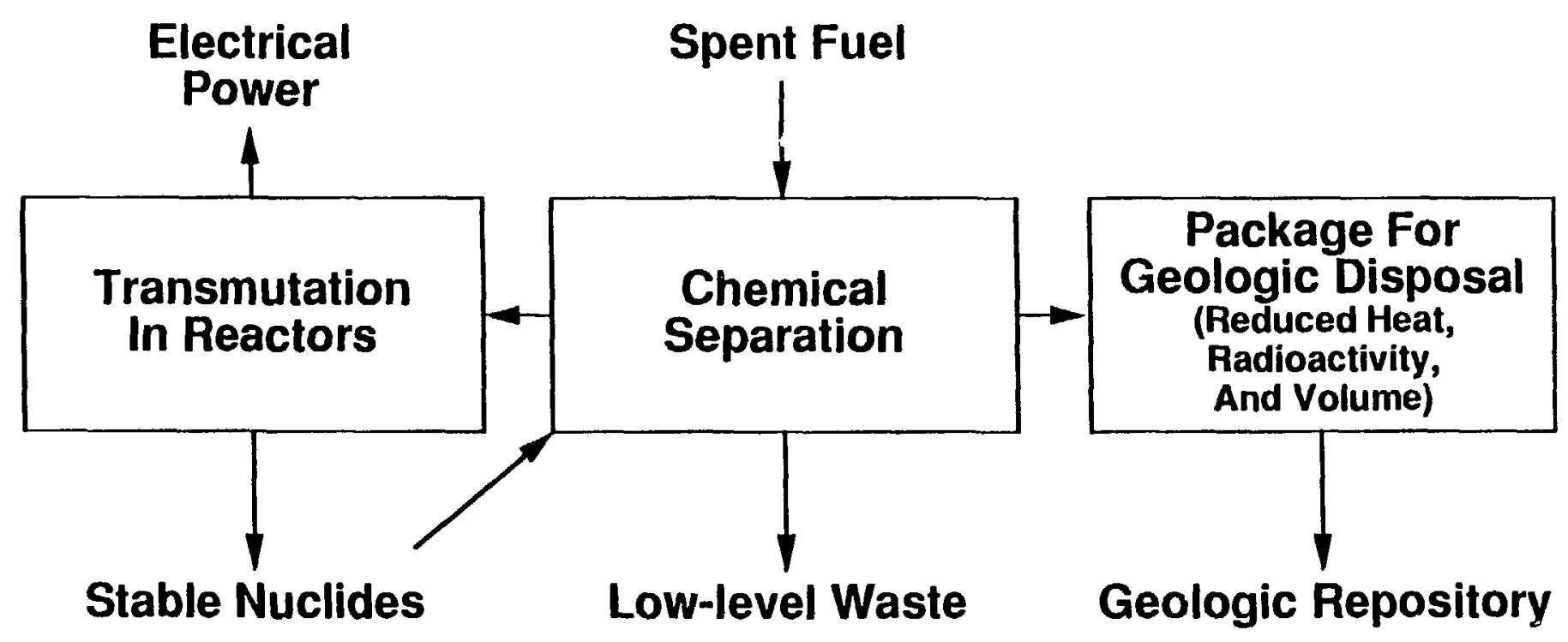




\section{Figure 9. CURE Process Flow Schematic}

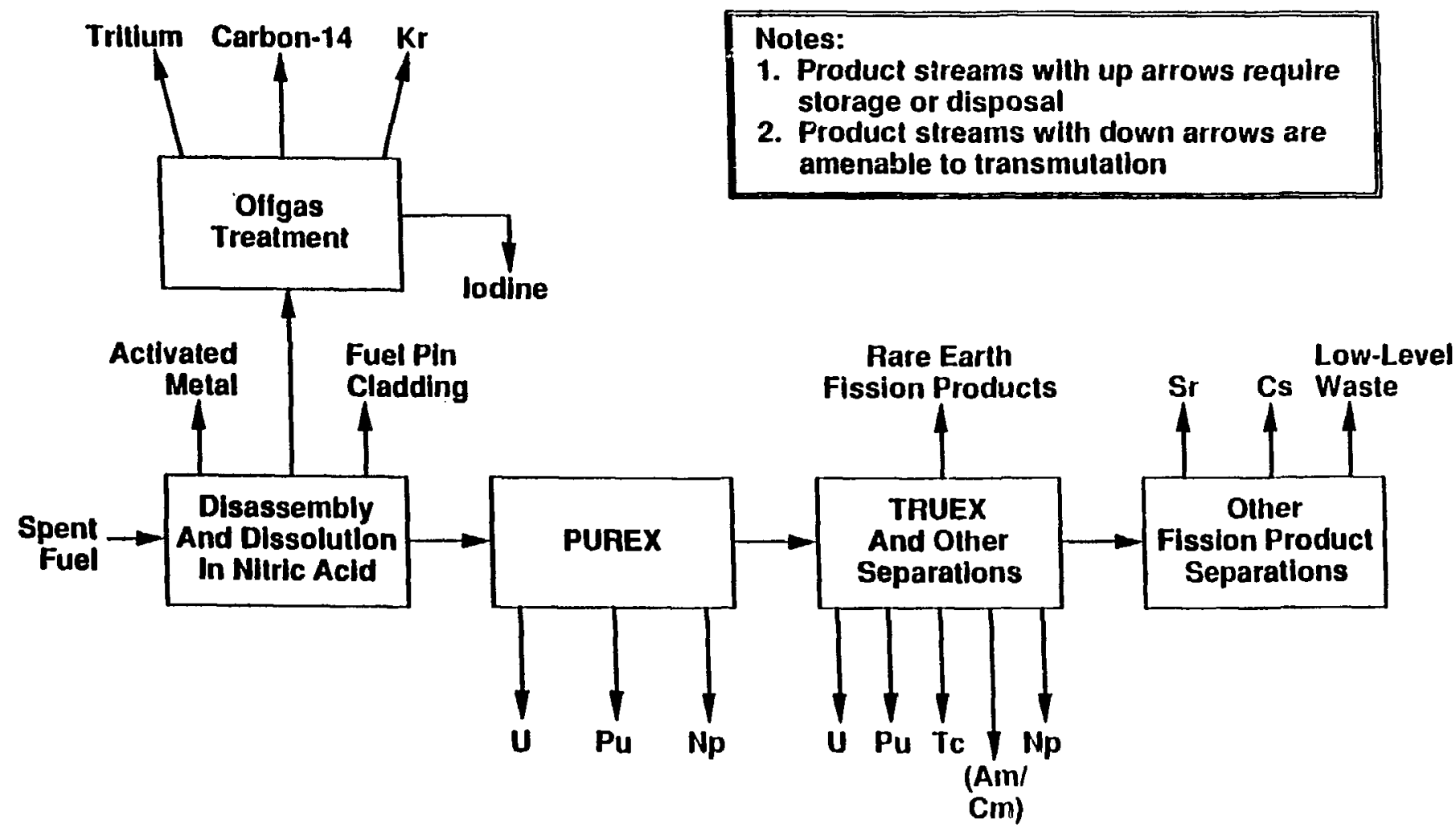


Compared with previous evaluations (accomplished 10 years ago) of the merits of the partitioning and transmutation (P-T) option, the CURE concept embraces newly developed nuclear reactor and chemical separations technology and new waste disposal principles. Specifically, the CURE concept:

1. Uses the combined aqueous-based Plutonium-Uranium Extraction (PUREX)/Transuranic Extraction (TRUEX) process to remove each actinide element efficiently, as well as Tc-99 from the final process waste.

2. Removes, purifies, and concentrates radioiodine from partitioning process offgas.

3. Uses advanced reactors and/or accelerators to convert long-lived actinides efficiently to beneficial products or to short-lived fission products or nonradioactive products.

4. Removes the heat-producing radionuclides, Sr-90 and Cs- 137 from the HLW for subsequent beneficial use and/or engineered storage for about 300 years.

\subsection{Other Current Perspectives on Waste Processing}

In previous sthdies (Refs. 9 and 10), researchers at the Oak Ridge National Laboratory (ORNL) compared the long-term repository risk reduction from actinide burning to increases in cost and contemporary risk. At that time (1977-80), they concluded that incentives for actinide burning did not exist. Recently (Ref. 11, published 11/90), the same group declared that "the now apparent challenges involved in characterizing and licensing a repository, combined with the specific repository regulations established in the last several years, appear to result in real incentives for actinide burning that will accrue during the next two decades." In particular, the authors cite a reduction in repository site characterization costs, an enhancement of repository site licensing, and an improvement in public acceptance.

However, the actinides are not the only significant hazards, as discussed in Reference 12. The author points out that "current analyses for repositories show that the doses from the fission products Tc-99, I-129, and Cs-135 are among the most significant long-term concerns."

The apparent contradictions between References 11 and 12 can be explained. If one focuses on current regulations and the hazards posed by all materials in the repository, in case of intrusion into the repository some time in the distant future, then the actinides are the major concern. However, if one focuses on the materials most likely to escape into the environment, driven only by natural forces, then some of the fission products become the major problem. Therefore, both references are correct to some degree. The CURE approach, and that adapted here, is to try to address all the potential problem materials under the assumption that the leaching/mobility questions are important. 


\section{THE PHOENIX CONCEPT}

\subsection{Characteristics of the Minor Actinides}

The through-put and composition of minor actinides from a $3410 \mathrm{MW}_{\mathrm{t}}$ light-water reactor (LWR) are indicated in Figure 10. These figures are based on the assumption of 10 years of decay, witheut separation, before processing. The composition estimated for project Omega (Ref. 3) is somewhat different, as the minor actinides are separated from the uranium and plutonium after 3 years, and the reprocessing is performed after only 8 years. However, assumptions regarding the minor actinide composition are not crucial to the design of a subcritical latice. The fission and capture cross sections for thermal neutrons, with respect to key actinides, are plotted in Figure 11. Note that only four of these isotopes are really fissionable with respect to thermal neutrons, and that only one isotope shown in Figure 10 is in this category. However, as these actinides capture neutrons, they climb the heavy-metal isotope buildup/decay chain, as shown in Figure 12.

The fission and capture cross sections with respect to fast neutrons are shown in Figure 13. Essentially all of the actinides will fast fission rather than capture fast neutrons. In addition, the number of neutrons per fission is in the range of 3 to 4 at high energies. Therefore, while the minor actinides are poisons in thermal reactors, they will fission in a fast spectrum reactor.

If one wishes to fission efficiently, and thereby eliminate the large inventory of LWR waste minor actinides, a fast-spectrum lattice is the best choice. As part of the Omega project (Ref. 3), the neutron spectra for different fast reactor designs were compared, as shown in Figure 14 (Note: "Safer" in Figure 14 refers to a smaller diameter fuel pin which lowers peak temperatures in the fuel, and does not refer to the "SAFR" LMR Concept developed by Rockwell International). In order to obtain the hardest spectrum, one would probably use a metallic fuel and a coolant that has little impact on the neutrons, e.g., helium or lead. However, metallic form minor actinide fuels would require considerable development and testing, and helium and lead have not been used in U.S. fast reactors. Therefore, although the LMR oxide fuel option may not have the highest neutronic efficiency, it is the best understood option, and would likely be efficient enough for the purpose of transmuting actinides. However, development of an advanced metallic form of minor actinide fuel would likely reduce the "burnup" reactivity increase and reduce the peak current required from the accelerator. Similarly, adaptation of a lead-based coolant would have significant advantages. Clearly, various cost-benefit trade-off studies should be performed once the basic concept has been established.

\subsection{Spallation and Neutronics}

With increased development of particle accelerators for applications ranging from research, to materials production and modification, and to the Strategic Defense Initiative, these machines have become larger, more powerful, and more efficient. The basic physics that results when high-energy charged particles are driven into targets of heavy elements has been known for several years. While empiricisms remain regarding the precise features of the intranuclear 
Figure 10. Minor Actinides Generated per year in a 3410 MWt LWR

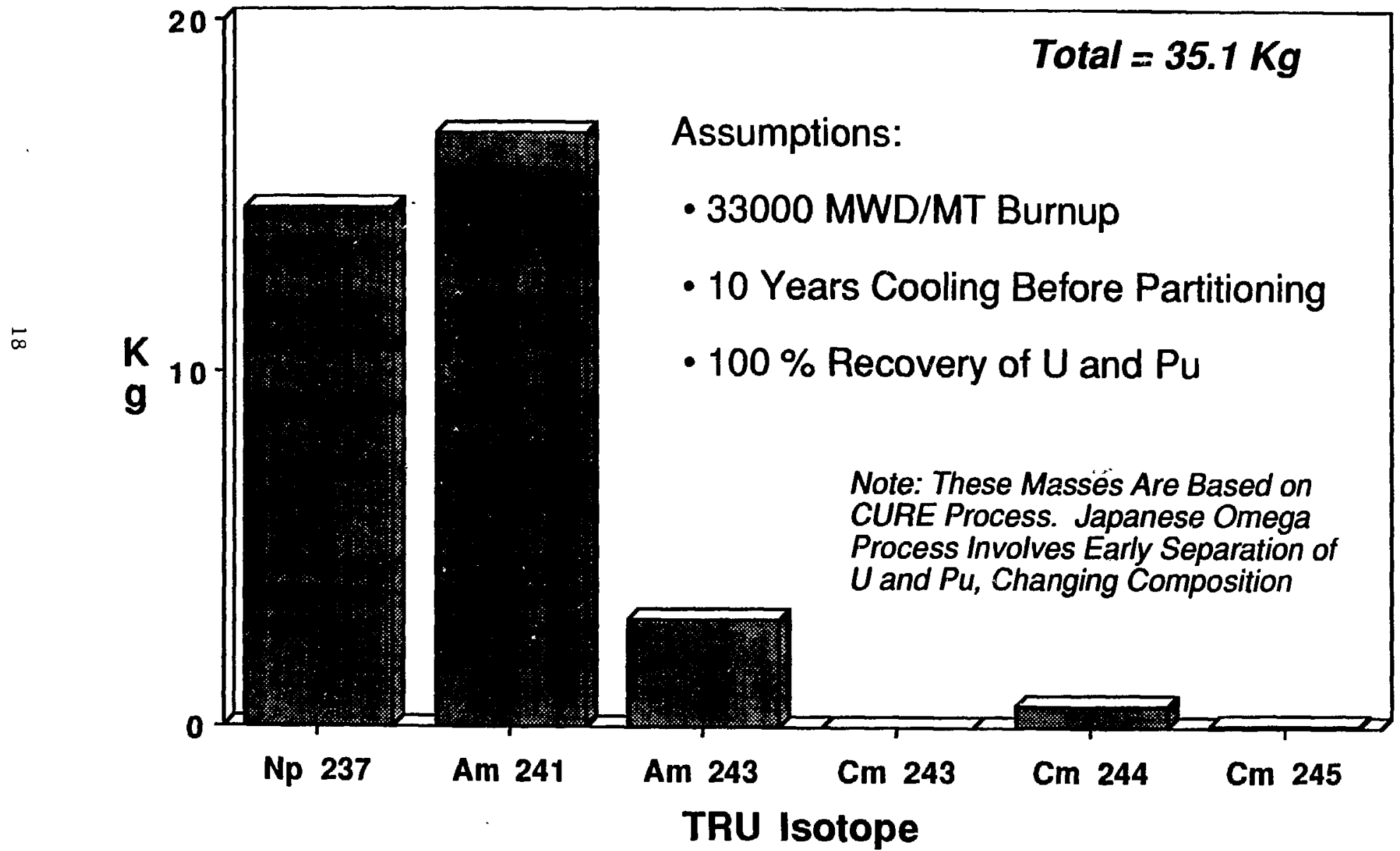


Figure 11. Thermal Cross Sections for Key Actinides

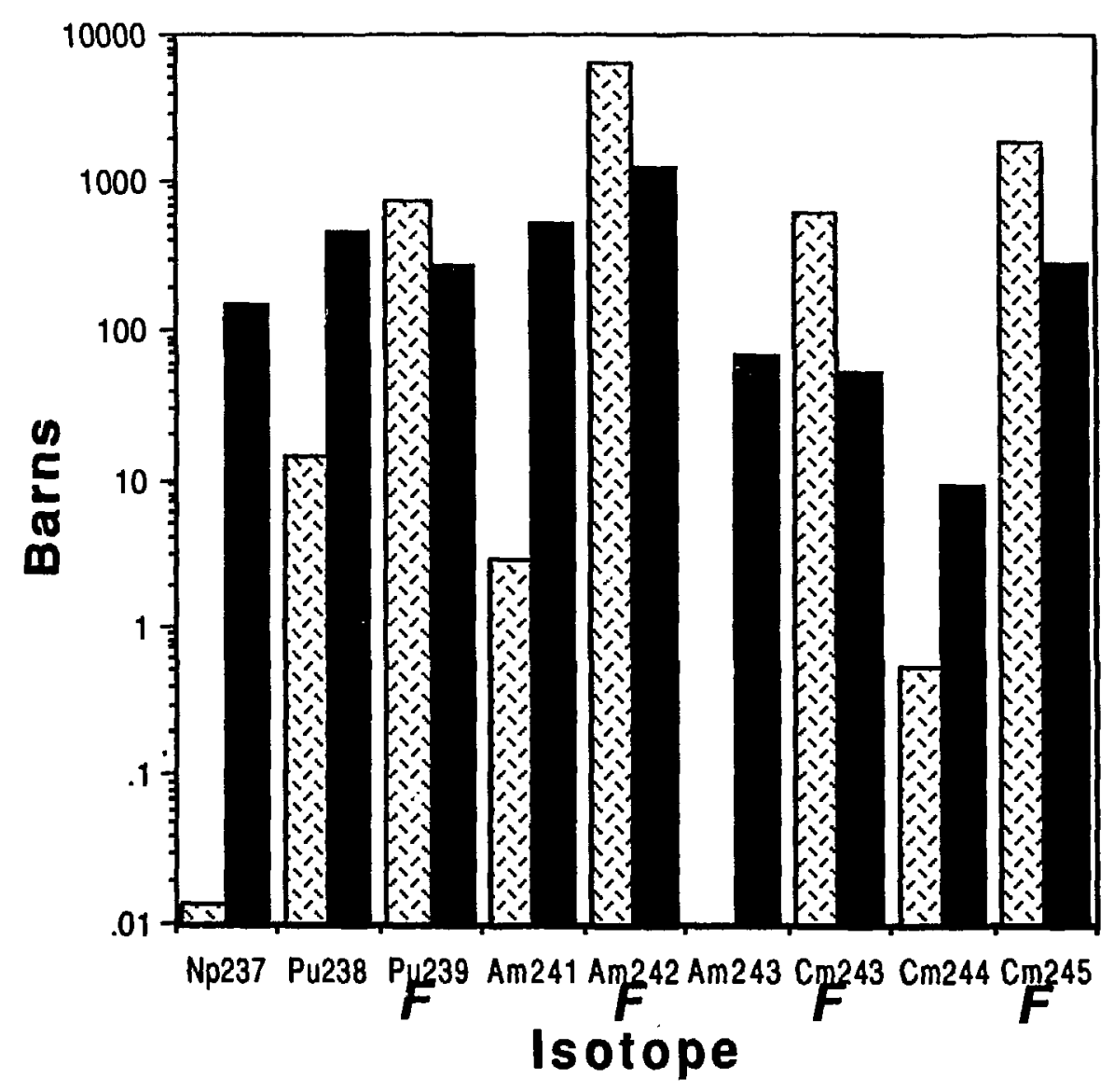

Fission
Capture

$F=$ Fissile (Predominantly) 


\section{Figure 12. Heavy Metal Isotope Buildup/Decay Chain.}

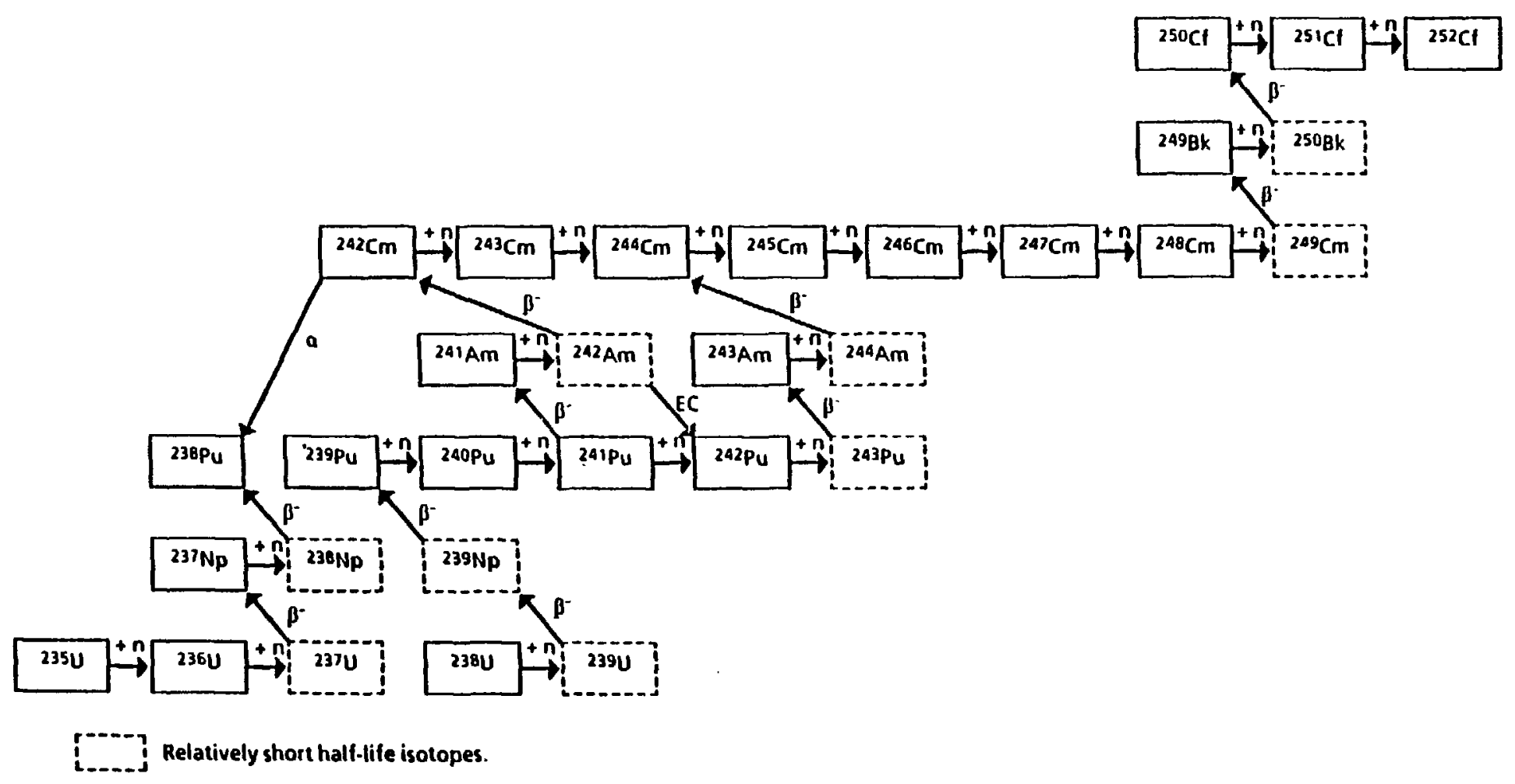


Figure 13. Fast Cross Sections for Key Actinides (1 to $20 \mathrm{MeV}$ )

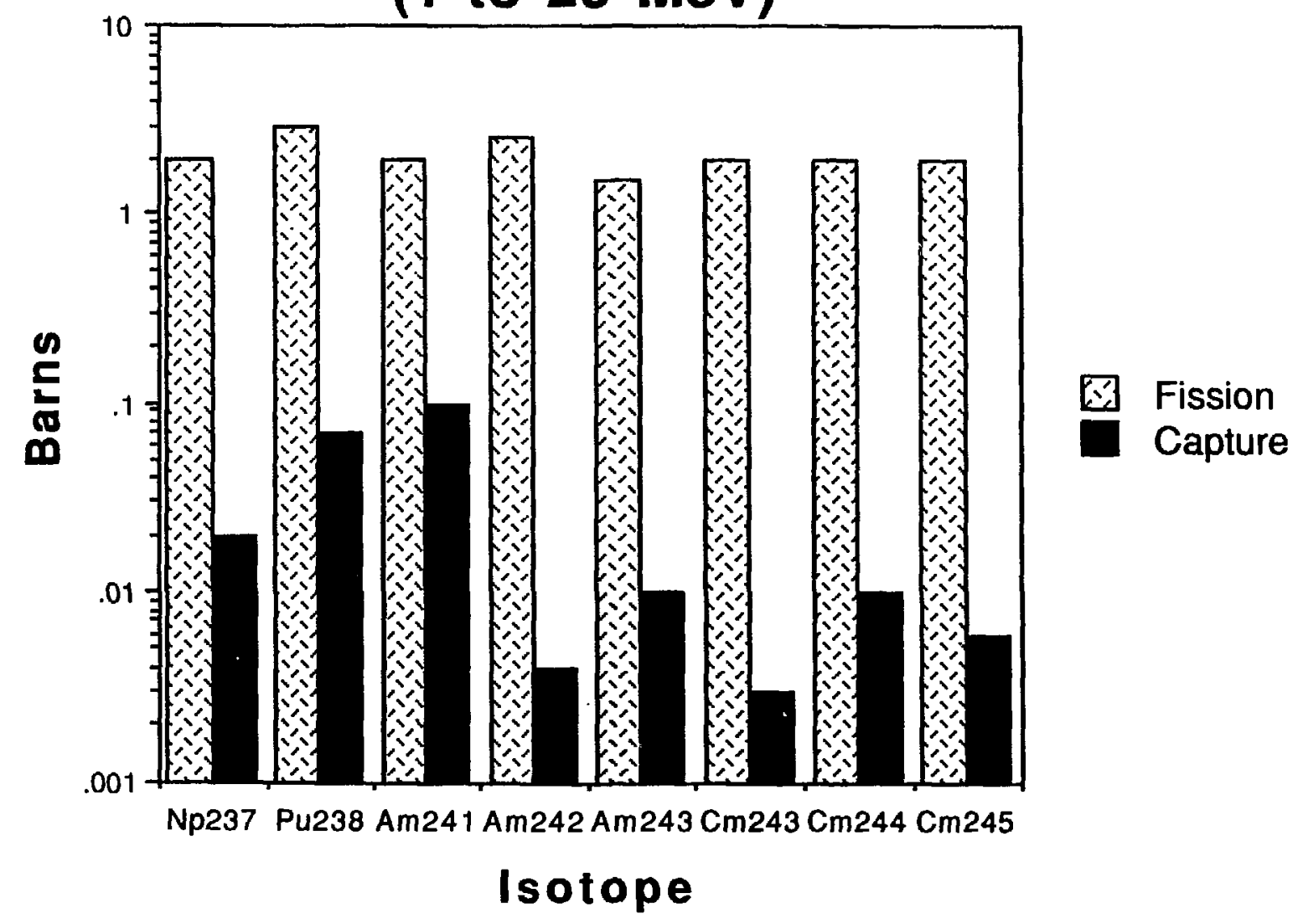




\section{Figure 14. Comparison of Neutron Spectra (Ref. 3)}

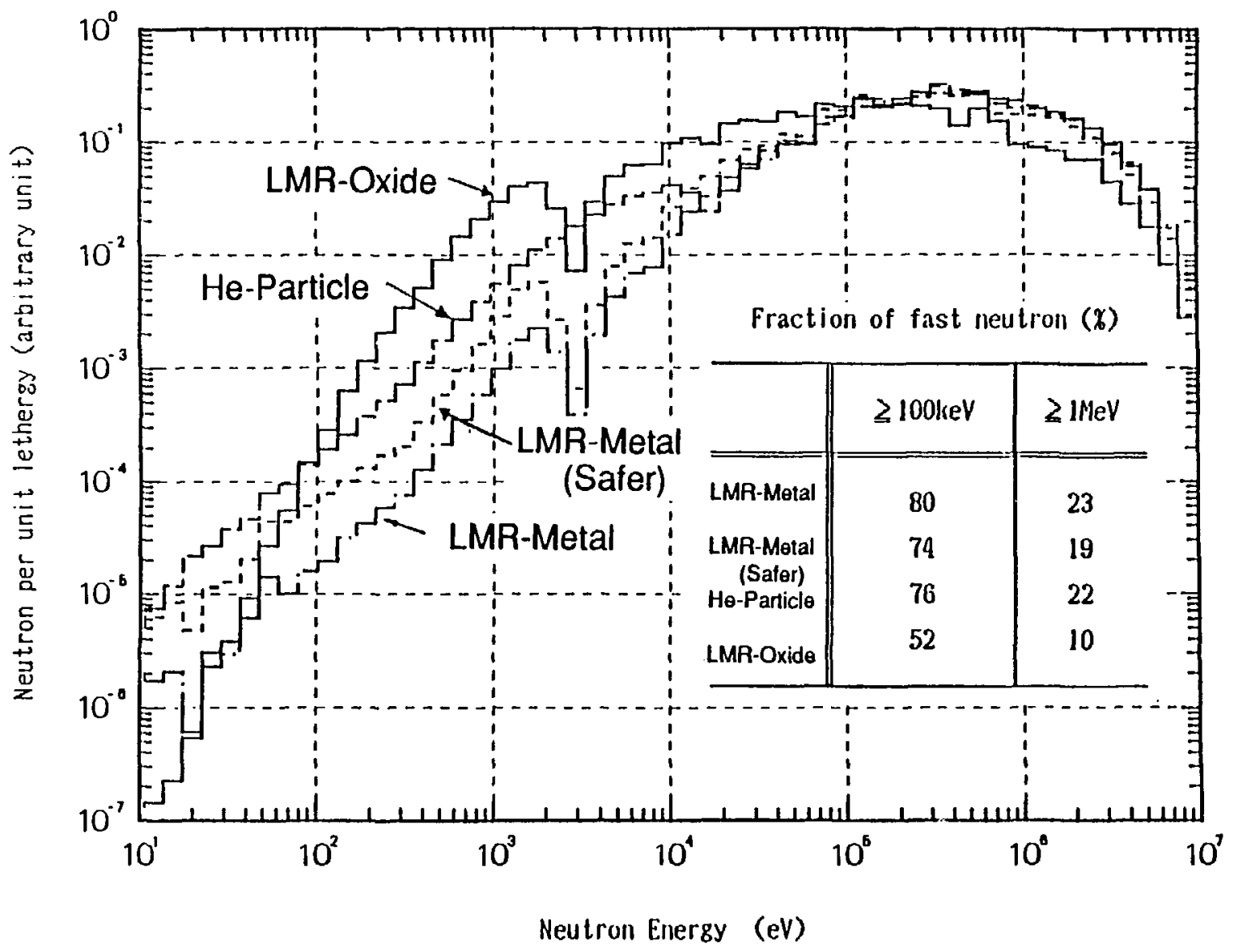


cascade process, there exist sufficient data and supporting theory to make reasonably accurate $(\sim \pm 15 \%)$ predictions for protons of a given energy level impacting on an actinide nucleus.

The high-energy proton-induced spallation and evaporation process is illustrated in Figure 15. The high-energy proton impacts on the nucleus of several TRU atoms (sequentially), causing destruction via direct "spallation" - a form of high-energy fission - or evaporation - in which a short-lived nucleus is created, and then quickly "evaporates" off neutrons and other particles.

Figures 16 and 17 indicate current best estimates, based on data and calculations, of the number of TRU nuclides spalled and the number of neutrons ultimately released, as a function of the incident proton energy in large targets (smaller than the PHOENIX targets, however). For an incident proton at $1.6 \mathrm{GeV}, 5$ or 6 nuclides of $\mathrm{Np}, \mathrm{Am}$, or $\mathrm{Cm}$ (they will be very similar) will be spalled. More importantly, about 50 neutrons will be knocked free as the proton penetrates the lattice; most of these resulting from evaporation.

If the target were to be of materials that could not fission, most of the neutrons would be absorbed in the lattice, and there would be little TRU conversion. However, in a subcritical lattice, the neutrons would be multiplied, as was shown in Figure 3. An effective multiplication factor of 0.9 results in the 50 neutrons becoming 450 neutrons. Most of these neutrons result from the fission of about 167 nuclides, again as was shown in Figure 3. In combination with the spalled nuclides, the single proton results in the destruction of 172 target nuclides. Should the multiplication factor be 0.95 , the same proton could trigger destruction of 357 of the TRU nuclides.

\subsection{Fission-Product Targets}

In order to keep a lattice containing minor actinides sufficiently subcritical with a hard neutronic spectrum, a significant fraction of neutrons must be leaked from the lattice, particularly as the reactivity increases with "burn-up" (which is really build-up in terms of fissile isotopes). The availability of neutrons provides an opportunity to reduce some of the inventory of problem fission products.

The transmutation chains for iodine and technetium are shown in Figure 18. While there is no real advantage to converting the I-127, it will comprise $24 \%$ of the iodine, and will therefore be present to divert some of the neutrons that could be better used to convert the I-129. In the case of all three base isotopes, Tc-99, I-129, and I-127, the absorption of one neutron creates a stable isotope, and the absorption of subsequent neutrons has little impact, except for wasting neutrons. 


\section{Figure 15. Uigh Energy Proton-Induced Nuclear Spallation Reaction}

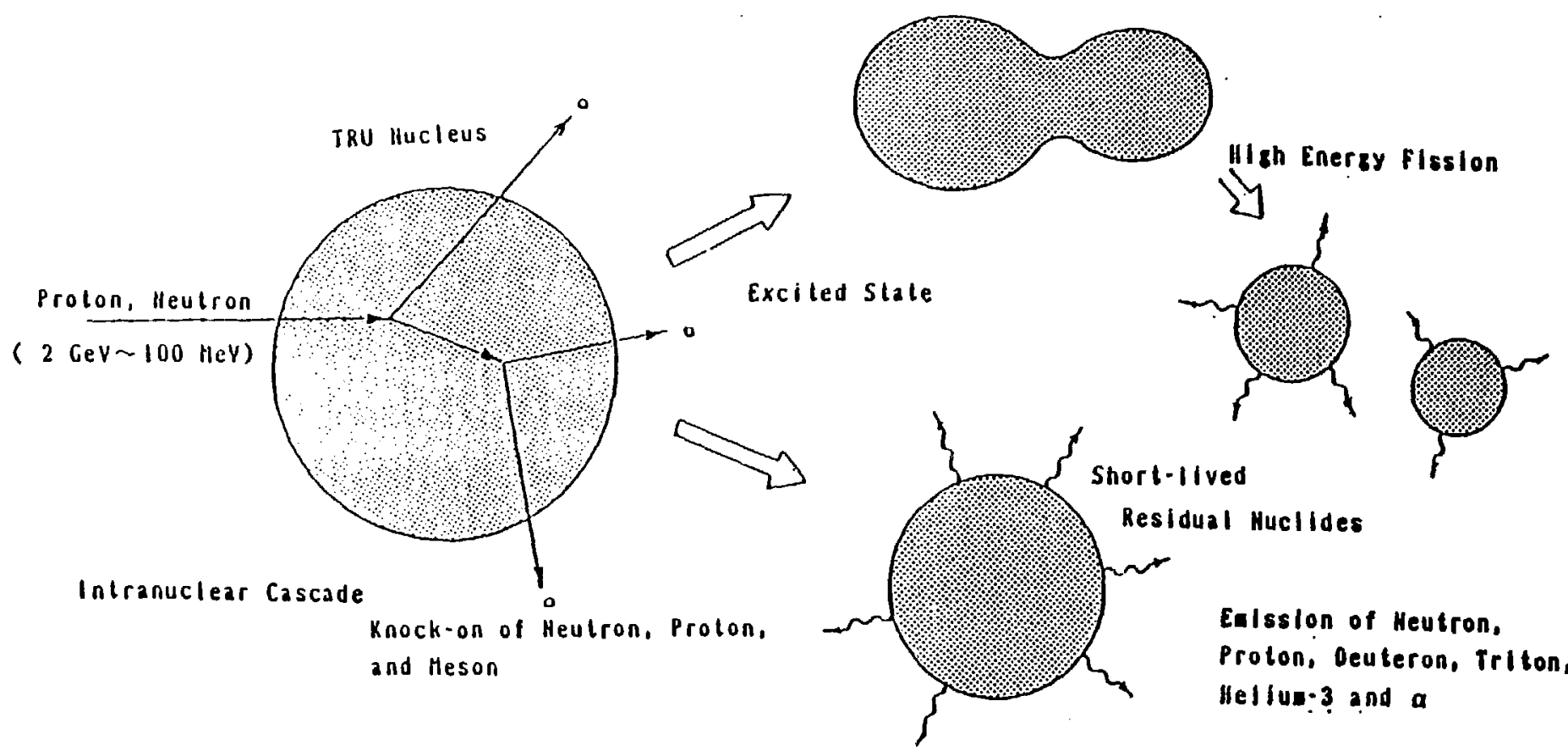

Particle Evaporation 
Figure 16. Number of Nuclide Spallated Per An Incident Proton Energy

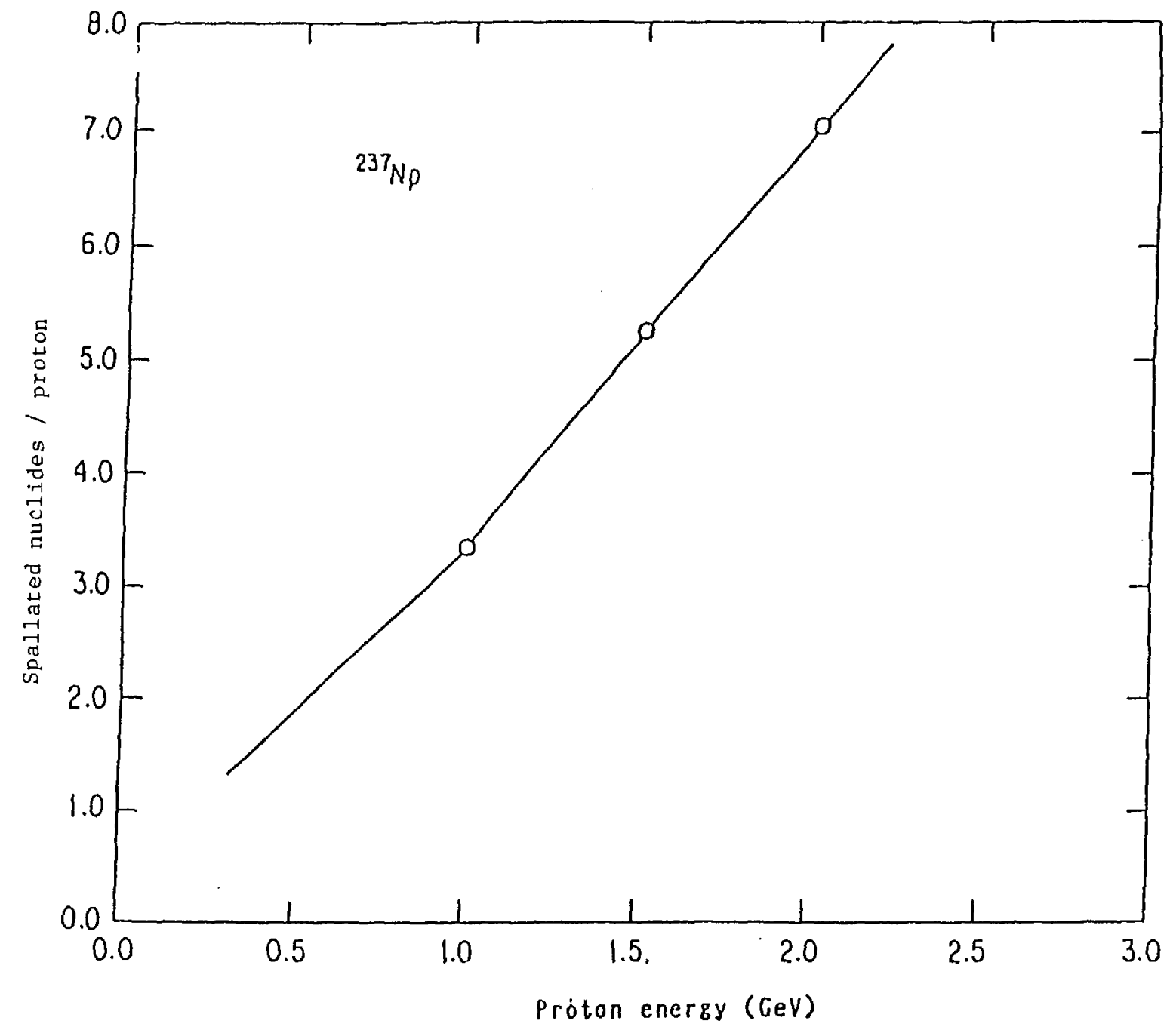


Figure 17. Number of Neutrons Produced Per An Incident Proton Energy

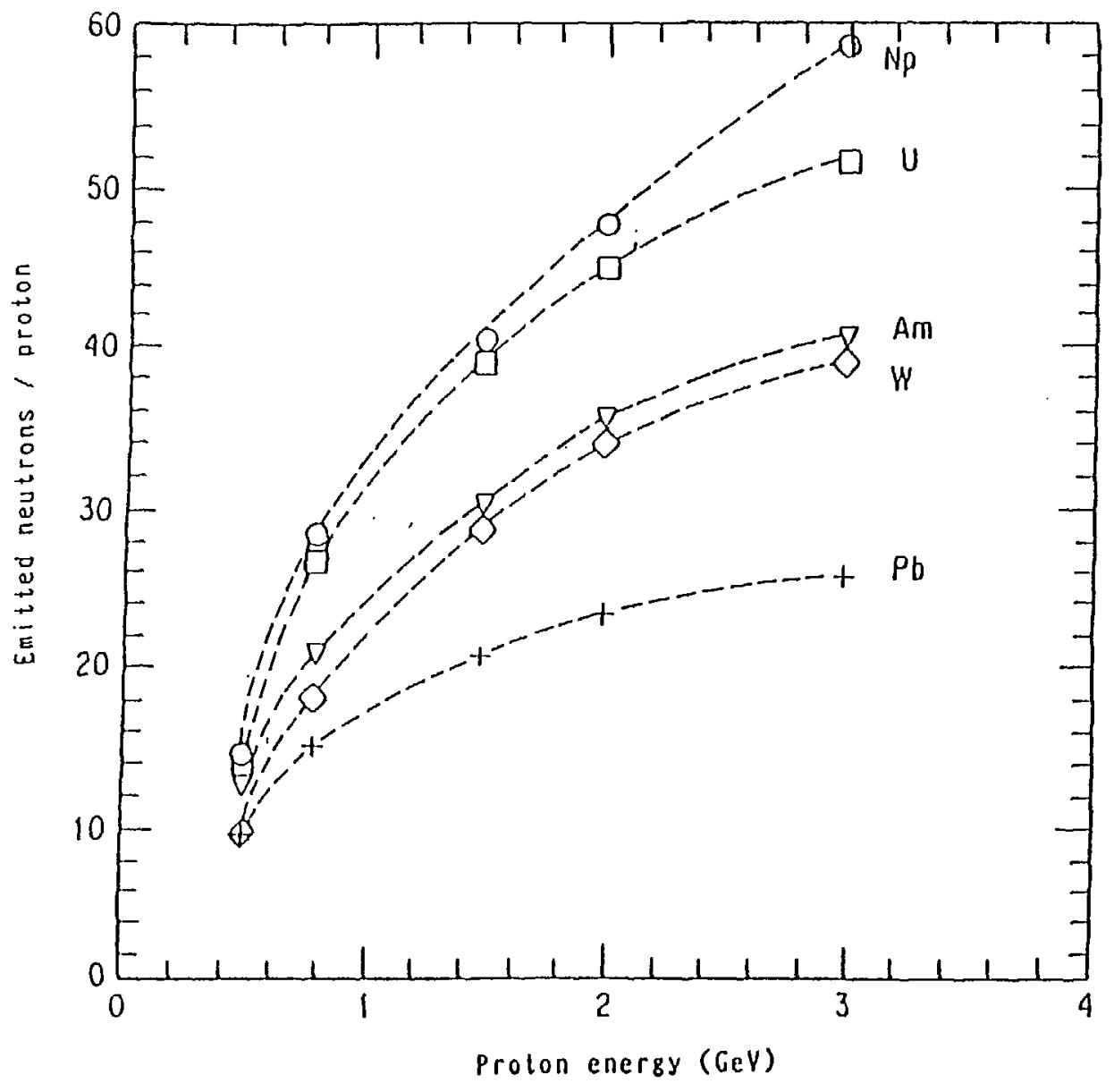


Figure 18. Transmutation Chains for lodine and Technetium

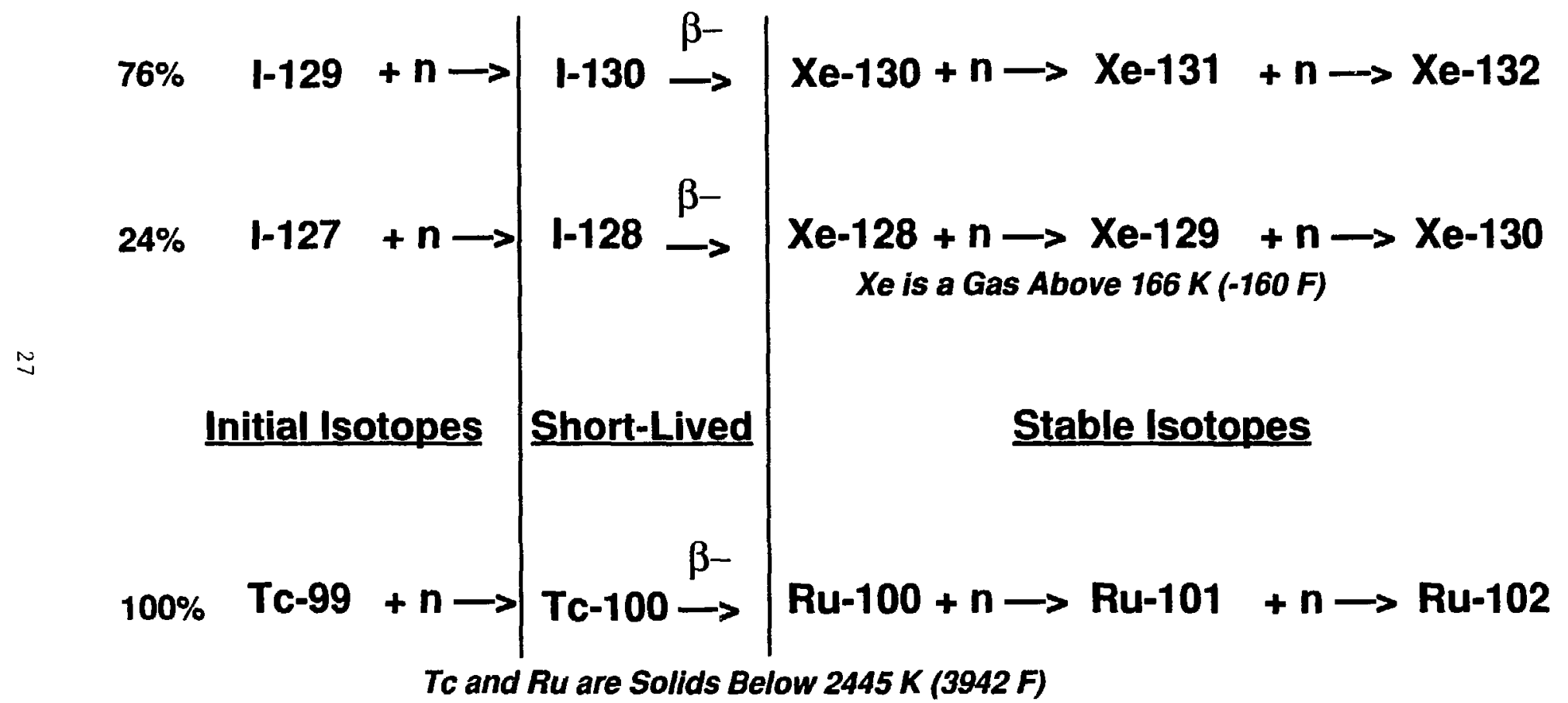


In terms of the chemistry, the two candidate fission products are very different. Xenon is gaseous at all temperatures of interest, and elemental iodine also has relatively low melting and boiling temperatures. Iodine targets would have to be designed carefully to retain the gasses. As these targets are composed of neutron absorbers, the leakage of these poisons could result in a significant reactivity increase. On the other hand, both technetium and ruthenium melt above $2400 \mathrm{~K}$ (3900F) and should be quite safe and stable, even in critical assemblies, i.e., reactors. 


\section{PHOENIX Design Studies}

\subsection{Lattice Types}

In selecting a lattice type, the principal objectives are a hard neutronic spectrum and a high degree of safety, especially with respect to heat removal. Of the three most credible coolant choices, sodium, helium, and lead, sodium has the best heat removal capabilities. It can be used in a relatively high-power-density lattice, has a high boiling temperature and excellent natural circulation capabilities, and conducts heat very well. Sodium also tends to soften the neutronic spectrum somewhat, but that is not currently perceived as a major problem. In contrast, while helium would have no effect on the spectrum, it does not conduct heat well and tends to leak from systems that are not tightly sealed. Lead would soften the spectrum considerably less than sodium, but it does not conduct heat quite as well as sodium, and there has been little experience with lead coolant systems within the U.S. However, the use of leadbismuth or lead-magnesium coolant systems would help the system efficiency by decreasing neutron captures and "burnup" reactivity swings, and is still being considered.

Regarding the fuel type, most liquid-metal reactors (LMRs) use oxide fuel, and it is believed that minor actinides could be substituted for the uranium and/or plutonium in the more common form of oxide fuel. While oxide fuels have high melting temperatures, the poor thermal conductivity and the neutron moderation impact of the oxygen atoms are notable disadvantages. If the metallic fuel developed as part of the Integral Fast Reactor (IFR) Program at ANL is utilized, the neutron spectrum would be somewhat hardened, which would decrease the "burnup" reactivity swing. However, substitution of americium, neptunium and curium for plutonium and uranium in the metal fuel would require some development effort. Although the melting point is lower for the metal fuel, the high thermal conductivity mitigates this problem somewhat. The "inherent shutdown" characteristics of the metallic fuel, in a reactor environment, would have little impact in PHOENIX, as the sub-critical lattice is driven by the accelerator. In addition, the inclusion of minor actinides significantly increases the sodium void worth and decreases the Doppler feedback (Ref. 13). Finally, in contrast to oxide and metal fuels, there are little data available for carbide or nitride fuels (although the French are now studying nitride fuels).

The Fast Flux Test Facility (FFTF) (Ref. 6) currently uses sodium coolant and oxide fuel, and provides an existing data base as well as a potential site for experiments on minor actinide fuel. The prototype PHOENIX lattice was based on the FFTF lattice, and scaled up to the required power level. As indicated in Figure 19, the lattice parameters would be essentially identical to FFTF, with the simple replacement of uranium - plutonium oxide fuel with minor actinide oxide fuel.

The principal reason for basing the target design on FFTF is credibility. Because most neutrons in the PHOENIX lattice will be the result of fissions, and most materials damage will be caused by those neutrons, there are strong reasons to believe that the PHOENIX target modules will experience materials damage very similar to that in FFTF. Therefore, we are fairly sure that this design can stand close scrutiny. On the other hand, this target is not optimized, and some improvements can be expected. 
Figure 19. PHOENIX Lattice Fuel Pins Are Currently Based on FFTF Oxide Fuel

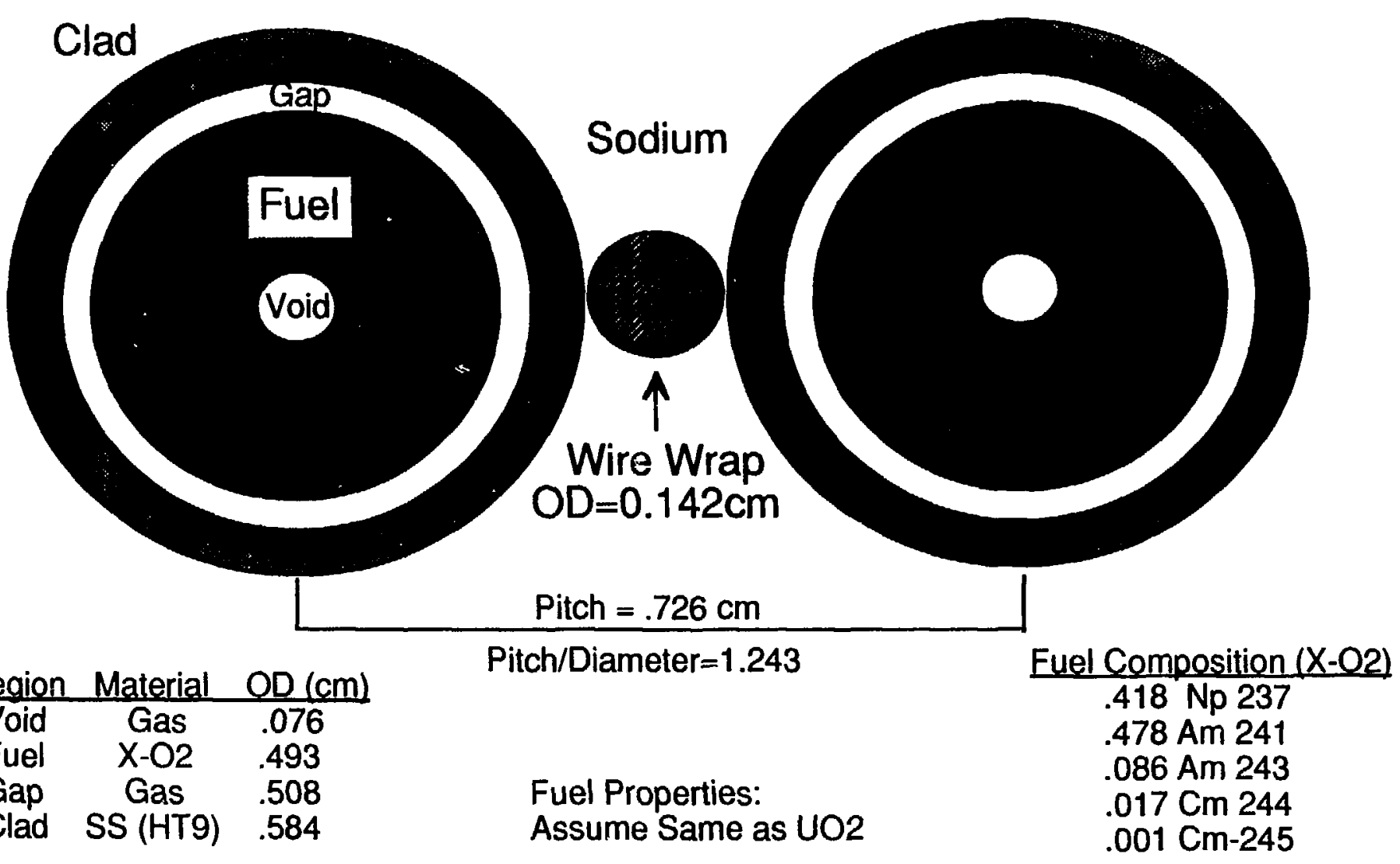




\subsection{Sizing and Design Calculations for Target Modules and Lattices}

Sizing of the full-scale PHOENIX facility is constrained by economic factors associated with the large linear accelerator. As was discussed in Section 1, a current of $104 \mathrm{~mA}$ is sufficient to drive a $k=0.9$ subcritical lattice at $3600 \mathrm{MW}_{\mathrm{t}}$. In principle, the $250 \mathrm{~mA}$ accelerator designed for tritium production (Refs. 4 and 5) could be utilized, as illustrated in Figure 20. A key feature of that accelerator design is the funneling of two $125 \mathrm{~mA}$ beams near the front of the machine. By limiting the PHOENIX accelerator to the $104 \mathrm{~mA}$ required to achieve $3600 \mathrm{MW}_{\mathrm{t}}$ in the lattice, we can eliminate the funneling aspect while retaining a significant margin below the current where funneling may be needed.

With respect to the lattice design, the extrapolation from the FFTF core is fairly modest. The number of protons and high energy neutrons (from direct collisions) is much smaller than the number of fission neutrons. In addition, the burnup level that is planned is lower than what is currently achievable, largely so the plutonium can be salvaged while it is mostly (86\%) Pu238. As the power peaking can be managed by beam shaping and lattice design, the use of a $3600 \mathrm{MW}$ lattice ( 9 modules) is not considered to be a large extrapolation.

The contribution of the reference PHOENIX facility, regarding the CURE process, is illustrated in Figure 21. Note, that while PHOENIX is converting only about $3 \mathrm{MT} / \mathrm{yr}$ of the $2500 \mathrm{MT} / \mathrm{yr}$ waste stream, it disposes of the most difficult portion.

Initial design and calculations for obtaining a preliminary estimate of the over-all dimensions of the target, and some of the detailed neutronic characteristics of the target modules were performed with the LAHET and MCNP Monte Carlo codes. The LAHET portion of the analyses considered the interaction of the incident $1.6 \mathrm{GeV}$ proton beam with the lattice and the subsequent generation of neutrons from high energy fission, spallation and evaporation events. The resulting neutrons are tracked until they leak from the lattice or scatter below some "low" energy cut-off $(-20 \mathrm{MeV})$. The neutron source below $\sim 20 \mathrm{MeV}$ is written out to a file as a function of energy and position within the lattice for the subsequent detailed slowing down calculation performed by MCNP. This analysis employs the latest ENDF/B-V cross sections in a detailed point representation. The highly heterogeneous nature of the target, coupled with the current limitations in the LAHET geometry lead to a two step approach. First a coupled LAHET/MCNP calculation was performed for an essentially homogenous 3-D rectangular representation of the target lattice. Subsequently, the lattice feature of the MCNP 384 code was used to represent the lattice/target module geometry in its full heterogenous detail to qualify the adequacy of the homogenous modelling employed in the coupled calculation. The results of these calculations provided a preliminary estimate for the size of the target of $188 \mathrm{~cm}$. wide, 82 $\mathrm{cm}$. deep, and $75 \mathrm{~cm}$. high. Estimates of the leakage across the faces of the target and the neutron flux, spectra, and heat generation rates were obtained.

\subsection{Burn-Up Calculations}

Based on the lattice composition and neutronic spectrum of FFTF (the accelerator should harden the spectrum somewhat), bumup calculations were performed using the ORIGEN Code (Ref. 14). We assumed the entire lattice was initialy composed of the minor actinides from the 


\section{Figure 20. $250 \mathrm{~mA}$ Accelerator with PHOENIX Beam Expander and Targets}

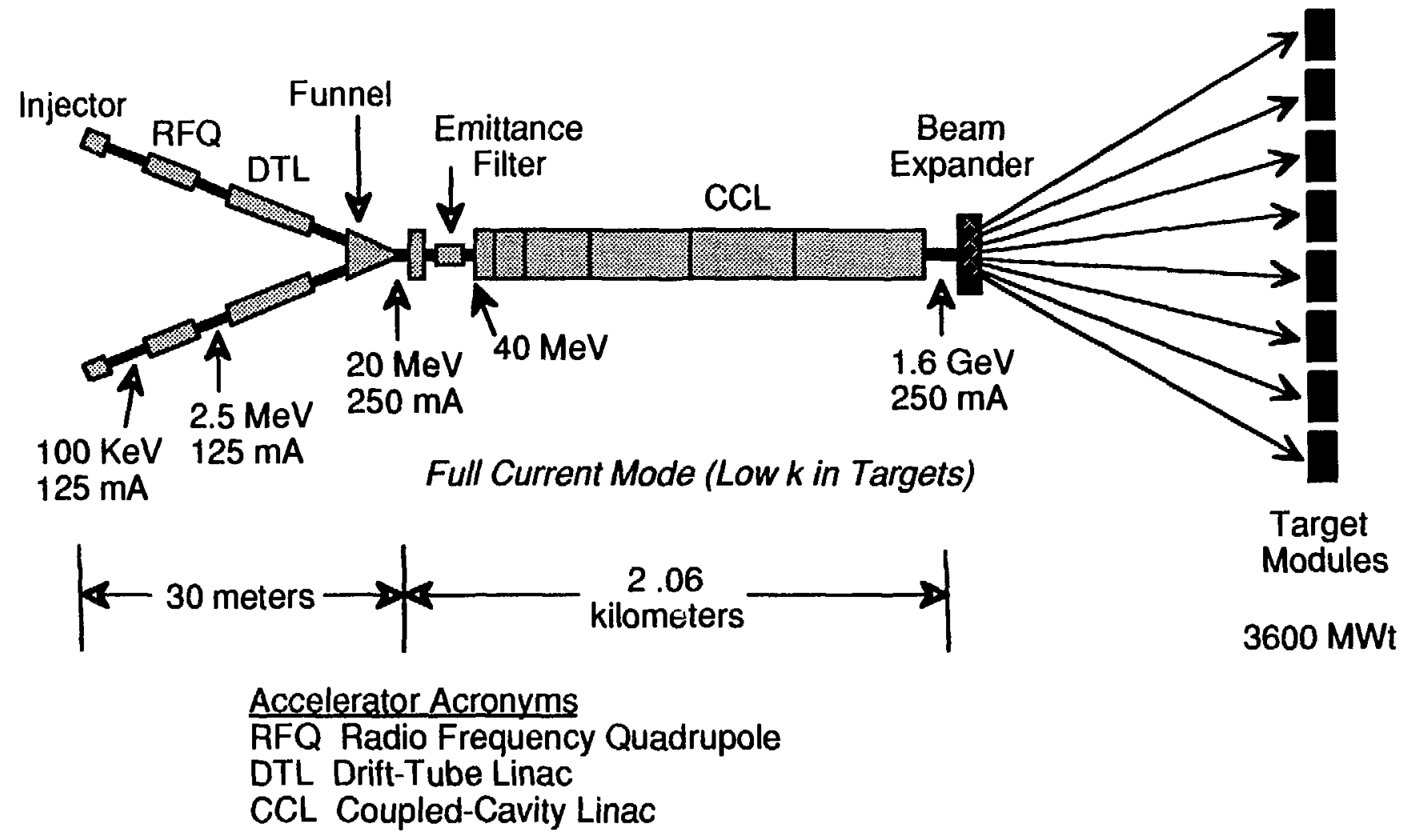

- 250 mA Accelerator System Designed by LANL \& Evaluated by ERAB

- 104 mA PHOENIX Accelerator Would Not Require Funneling 
Figure 21. PHOENIX Transmutes the WastesThat Can't Go Into Thermal Reactors

2500 MT/Yr LWR Wastes from 75 1000 MWe

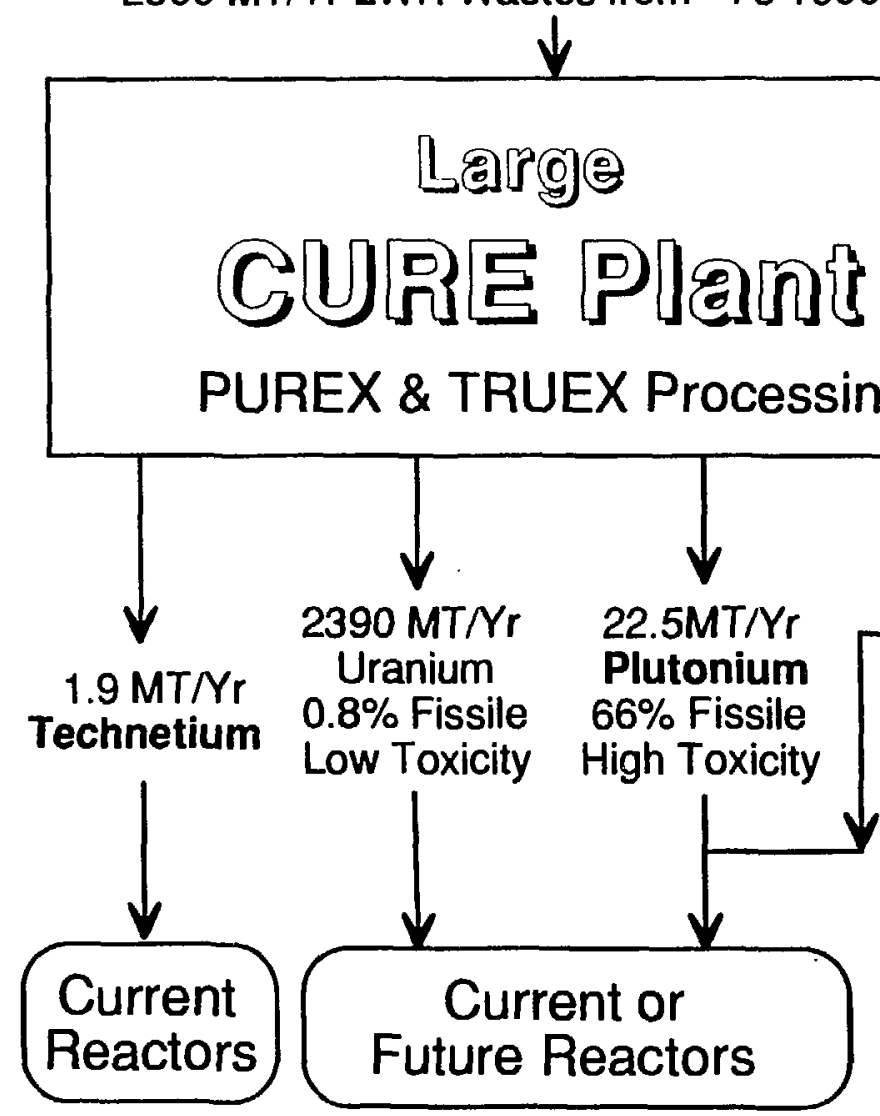

$\Rightarrow$ Recycling Option
Operational Mode: Salvage Plutonium

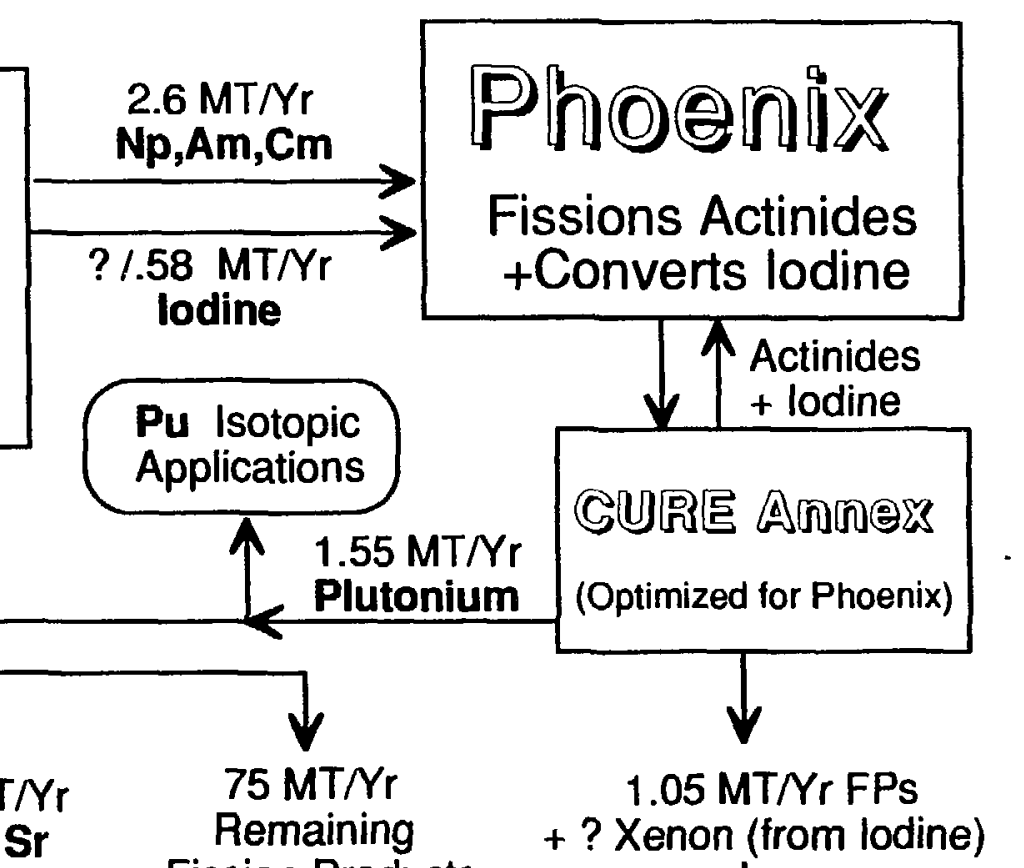


LWRs via the CURE processing facility. It was assumed that every 2 years the fuel was removed and reprocessed. A two-year decay while the "spent fuel" is cooled, processed, and reloaded was factored into the analysis. During this two-year period all fission products and the plutonium are assumed removed, and minor actinide makeup is assumed to be added, restoring the initial "fuel" loading.

The results of a 6-cycle, 12 year burnup calculation are shown in Figures 22 and 23 . The principal reason for recycling every two years is to remove the plutonium while it is largely Pu238. This has at least two advantages. First, the structural materials only have to survive 18 months of burnup ( 24 calendar months), which should be easily attainable (HT9 could likely survive longer exposures but some testing would be required). Second, the burn-up reactivity increases are reduced so they can be more easily compensated.

As shown in Figure 22, a near-equilibrium cycle is reached within a few years. This has several advantages, including the fact that an old target (fuel in for 7 th cycle, for example) will behave much like a new target.

The increasing inventory of fissile isotopes causes the neutron multiplier to increase, as indicated in Figure 22. Because ORIGEN does not fully account for geometric factors, the increase in $\mathrm{k}$ plotted in Figure 22 is only approximately correct. This increase can be overcome by varying the beam current, by changing the geometry (more leakage) from cycle-to-cycle, and by using burn-up compensating poisons.

The isotopic concentrations are shown in Figure 23. The two-year cycle produces little Pu-239 and only a modest amount of Pu-242. The fraction of Pu-238 at the end of each 2 year cycle varies between $85 \%$ and $87 \%$. There is little variation in the Np-237 inventory from cycle-to-cycle. The gradual increase in Am-243 relative to Am-241 is notable, but it appears to be well stabilized by the 6 th cycle.

Pu-238, because of its relatively "short" half-life of 87.7 years, is considered to be a good power source for use in the space program. For such usage, the Pu-238 must be fairly pure and contain only very small amounts of Pu-236 ( 3 year half-life). With the hard neutronic spectrum in PHOENIX, Pu-236 production will likely be too high in the Np-237 portion of the fuel. Therefore, in order to provide Pu-238 for space applications, the Am-241 and Np-237 would need to be separated physically. This has not been evaluated, but through careful engineering at least one-third of the Pu-238 production could probably be used for space applications.

\subsection{Modular Design}

While PHOENIX is designed to keep up with the waste stream from about 75 LWRs if fully loaded, it need not always run in such a mode. Initially, there may not be 24 metric tonnes of processed minor actinides available for loading. Also, during the first years of PHOENIX operation, a lower target loading and, therefore, a lower demand for beam current would make for an easier start-up and testing phase for the large linear accelerator. Finally, the use of 
Figure 22. Reactivity Increase \& Mass of Principal Actinides During First 12 Years of Burn-Up in 3600 MWt PHOENIX Lattice, Assuming Plutonium Removed During Reprocessing

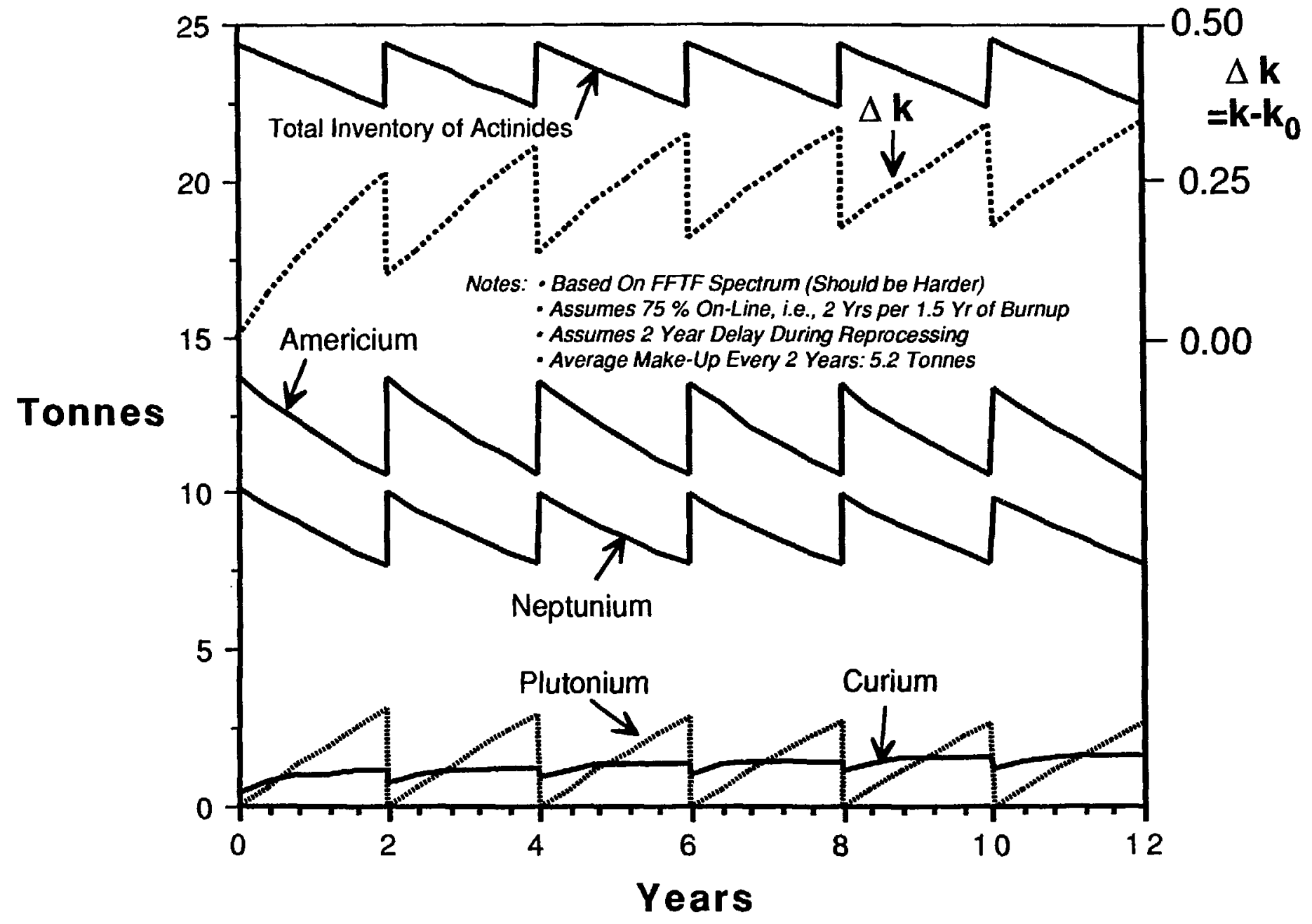


Figure 23. Mass of Key Isotopes During First 12 Years of Burn-Up in $3600 \mathrm{MWt}$ PHOENIX Lattice, Assuming Pu and U Removed During Reprocessing

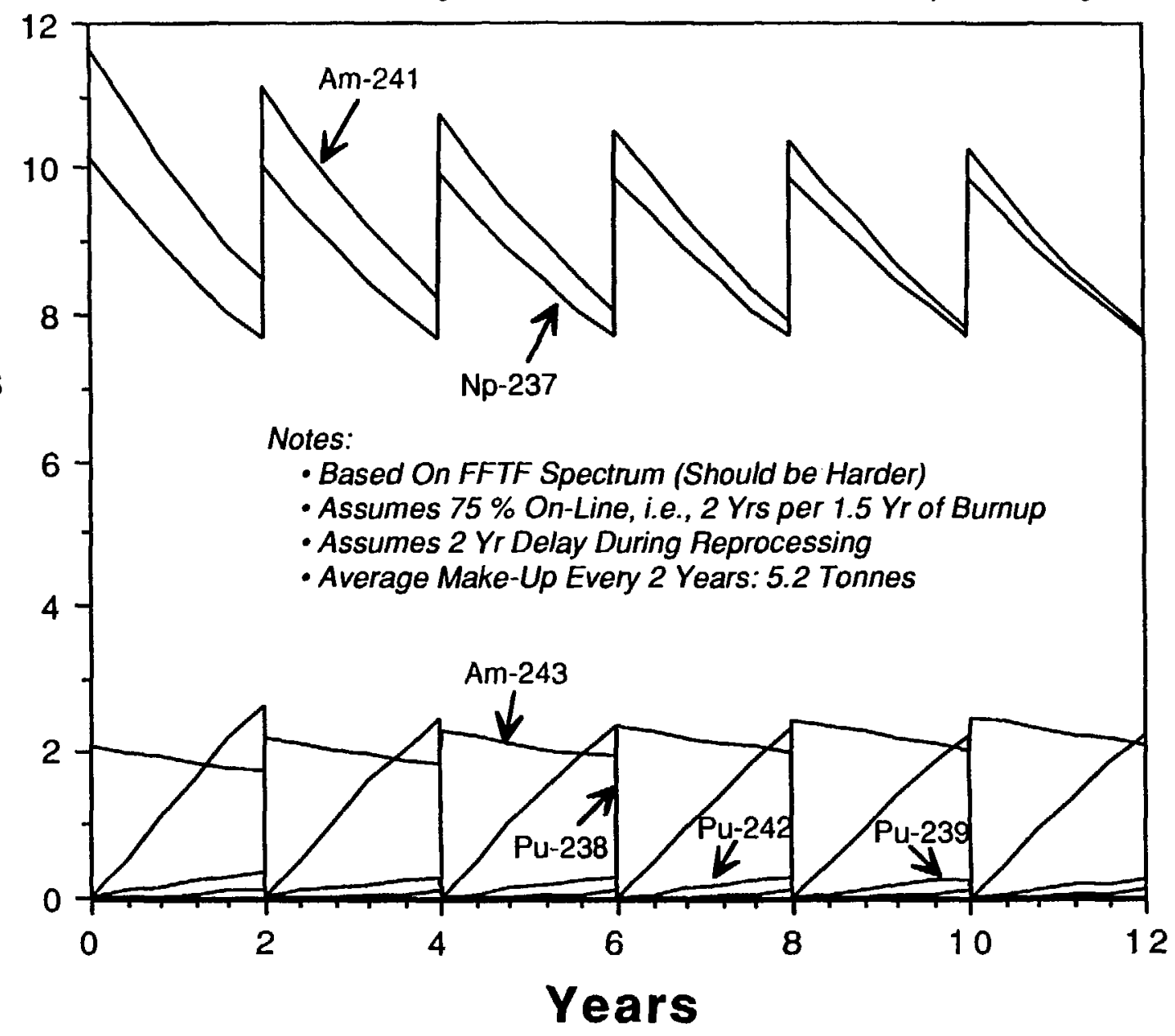


modular targets would allow the removal of a troublesome target module without shutting down the machine for a prolonged period of time.

The preliminary size, shape, and important characteristics of the eight $450 \mathrm{MW}$ PHOENIX Target Modules are indicated in Figure 24. Lattice characteristics inside the hexcans are very similar to FFTF. However, the shape of the module, .75 $\mathrm{M}$ high by $.82 \mathrm{M}$ deep by $1.88 \mathrm{M}$ across, is set to allow for considerable neutron leakage. This shape also maintains a negative sodium void reactivity worth and reduces the peaking into the target (calculated to be near the center, front-to-back). The fact that most neutron leakage is out the top and bottom or the front and back means that several modules could be placed side-by-side without significantly impacting on the neutron multiplication factor. (It is noted that more detailed physics calculations must be performed before the shape of the module can be finalized; it may need to be deepened to reduce the leakage somewhat).

The arrangement of the eight PHOENIX target modules within the vacuum chamber is illustrated in Figures 25 and 26. Each module is designed to be removed from the vacuum chamber for reloading. PHOENIX could run effectively even with only one target chamber, although its throughput and efficiency are highest if all targets are loaded.

Based on the preliminary design, the fission product targets indicated in Figure 26 would be Iodine-129 (in a stable-compound form) possibly cooled by $\mathrm{D}_{2} \mathrm{O}$ (Heavy Water). The $\mathrm{D}_{2} \mathrm{O}$ would serve as a moderator, because the I-129 is most likely to absorb epi-thermal neutrons. Because water and sodium react violently if mixed, no water-cooled targets would be located close to the sodium piping. Instead, some other moderator, such as graphite or beryllium, would be located between the sodium pipes and water cooled fission product targets.

The region in and around the vacuum chamber will become highly radioactive after a few months of operation. Handling of target modules and fission product targets will be handled remotely, which is a major reason for using modular target units. Operationally, after the accelerator has been shut down for a few weeks, a module would be removed to a remote cooling area. A fresh module is then moved into the vacuum chamber and the accelerator is then restarted.

\subsection{Accelerator Performance at Reduced Loadings}

Regarding the operation of PHOENIX at reduced target loadings, one important factor is that the machine can be run at different duty factors in order to produce different currents, as illustrated in Figure 27. If the machine is running at a $60 \%$ duty factor (i.e., 0.6 ), it is driving current for 600 milliseconds out of every 1 second, and is otherwise idle. (If the pulsing is frequent it does not cause problems with the heat conduction, and other target functions). For an assumed $60 \%$ duty factor, a current of $62 \mathrm{~mA}$ (average) would be delivered, which requires 265 MW of electricity. Such a current could drive the PHOENIX lattice at $3600 \mathrm{MW}_{\mathrm{t}}$ if the k-effective was slightly under 0.94 . Even if the $k$-effective is significantly less than 0.9 , the accelerator could drive the lattice at lower power levels, at least until the reactivity builds to 0.9 . In an extreme case, PHOENIX could be run between $\mathrm{k}=0.7$ (reduced power levels) and $\mathrm{k}=$ 


\section{Figure 24. PHOENIX 450 MWt Sub-Critical Module}

Approximate Size: 0.75 Meter High, 0.82 Meters Deep, and 1.88 Meters Across Module Contains 124 Hex-Cans $\left(4^{*} 16+4^{*} 15\right) \quad(+1 \mathrm{~cm}$ perimeter gap)

Inside Module/Outside Hex-Cans: Helium Gas + Sodium Leak Detection System

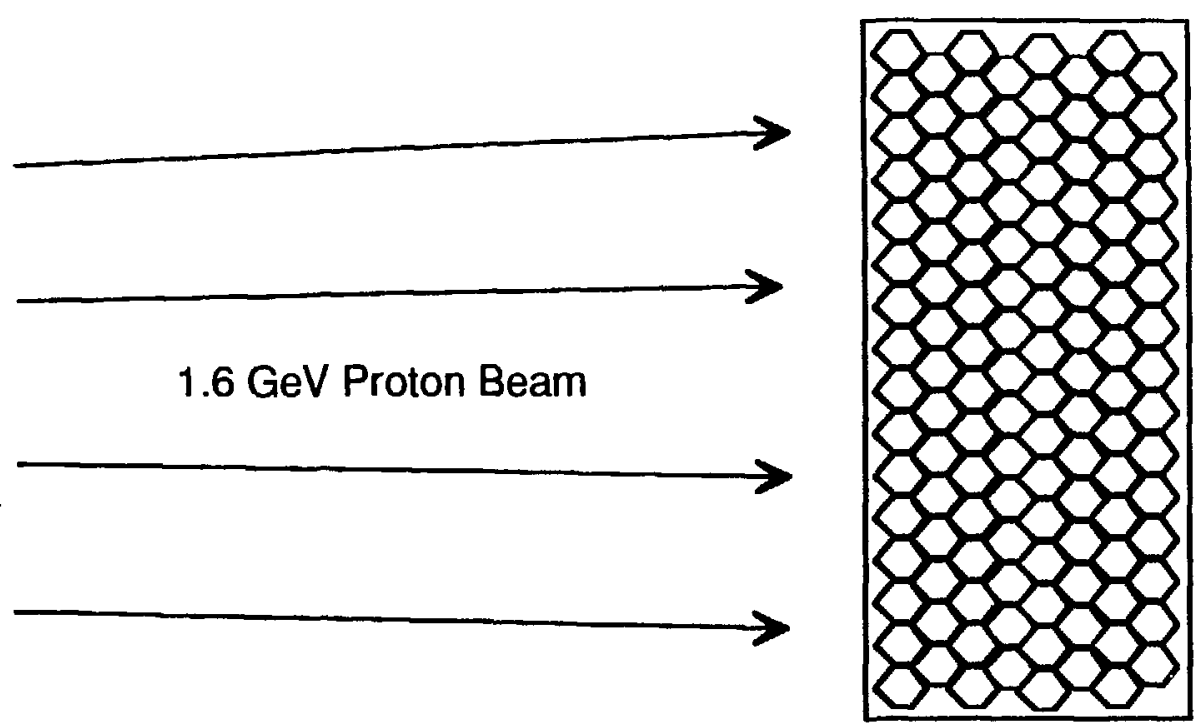

Each Hex-Can : 116 meters flat-to-flat, 4.7 meters high, and containing 217 fuel pins, flow area $=.00432 \mathrm{~m} 2$ Nominal lattice spacing $=.120$ meters, gap between assemblies: 0.0033 meters (collars)

Operating conditions: assembly flow $=24 \mathrm{~kg} / \mathrm{s}$, inlet temp $=560 \mathrm{~K}$, outlet temp $=760 \mathrm{~K}$, pressure $=0.5 \mathrm{MPa}$

Pressure drop $=0.806 \mathrm{MPa}$, average velocity $=6.4 \mathrm{~m} / \mathrm{s}$, average sodium density $=850 \mathrm{~kg} / \mathrm{m} 3$ 


\section{Figure 25. PHOENIX Modular Lattice Concept}

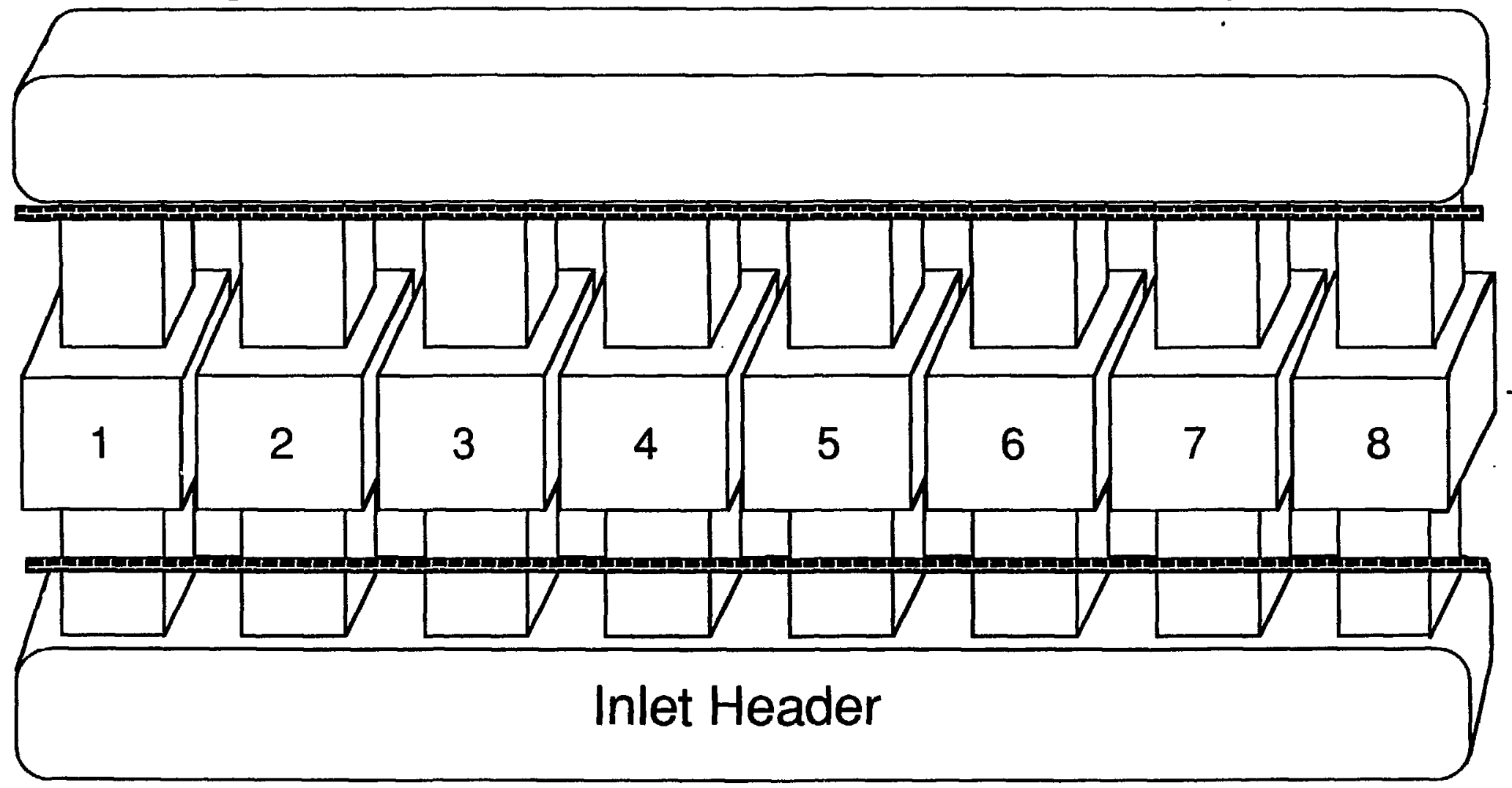

Each $450 \mathrm{MWt}$ Module Contains 3 MT of Minor Actinides And Fissions $132 \mathrm{~kg} / \mathrm{yr}$

- Each Module In Lattice for 2 Years ( 20\% Conversion) \& Then Reloaded in 2 Years

- All Processing of Module to be Performed Outside Vacuum Chamber 


\section{Figure 26. PHOENIX Target Chamber from Three Perspectives}
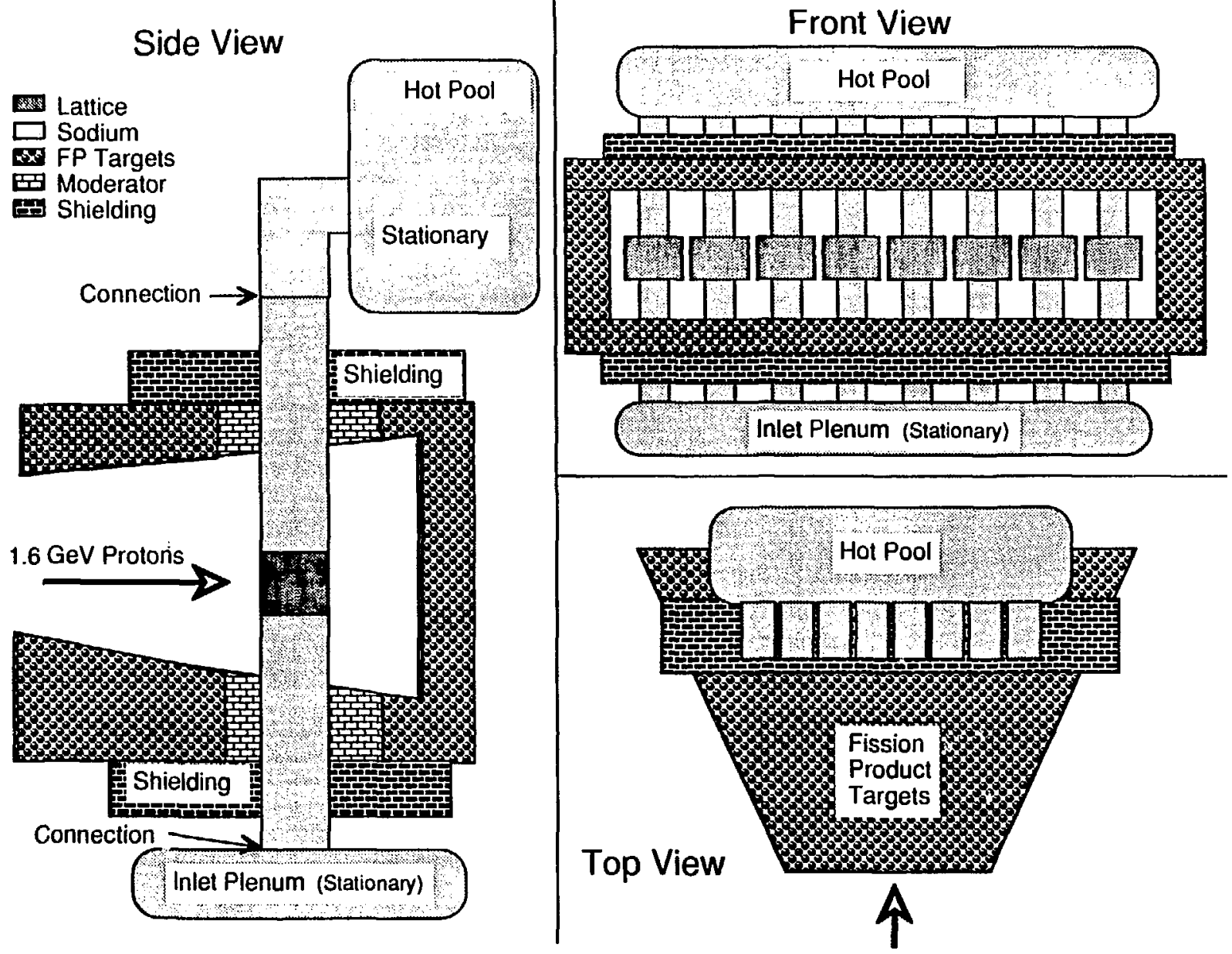
Figure 27. Power Requirements, Beam Current, and Effective Multiplier $k$ as function of Duty Factor for 104 mA LINAC with $3600 \mathrm{MWt}$ Lattice

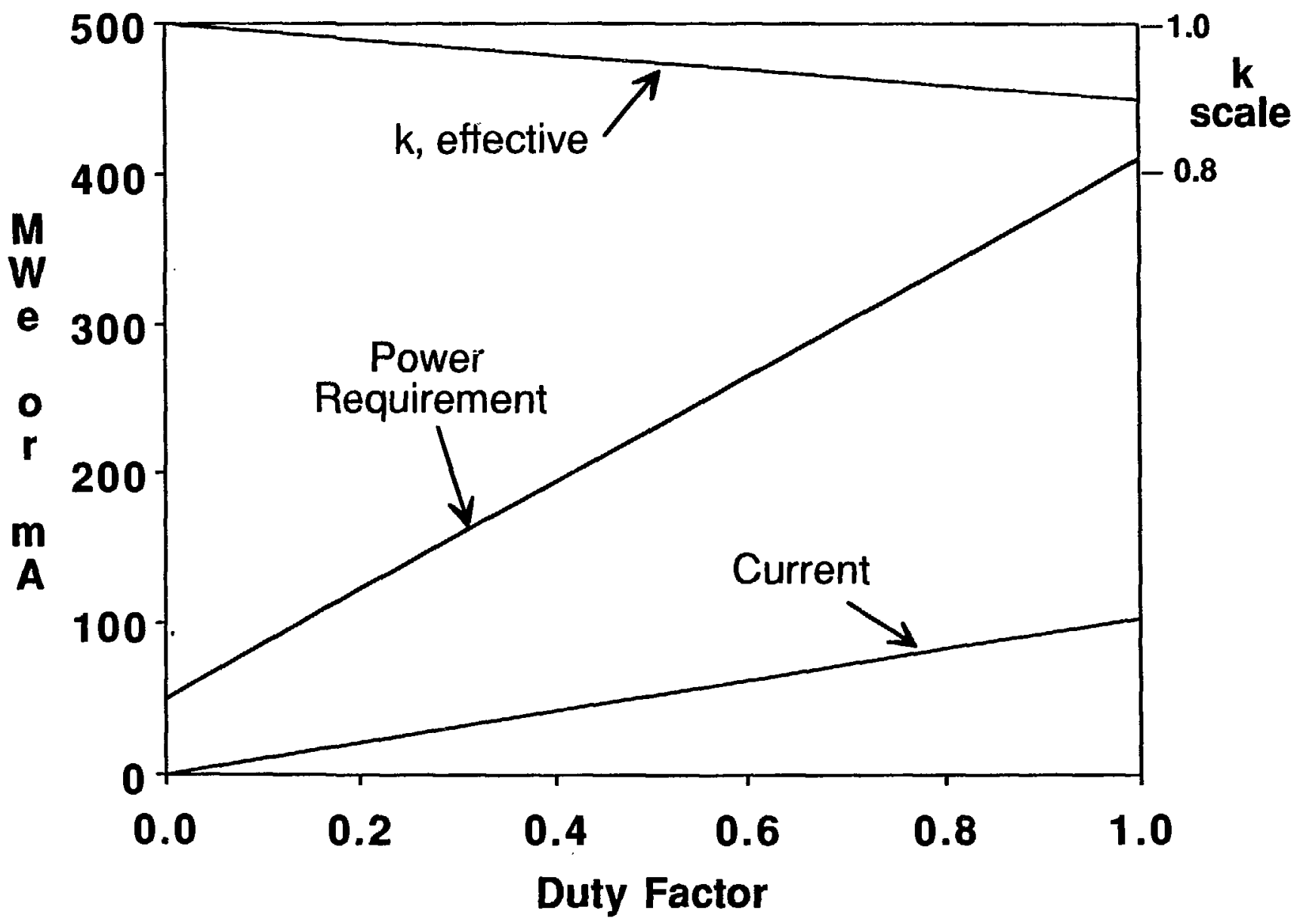


0.95 , with the accelerator current dropping from $104 \mathrm{~mA}$ down to around $50 \mathrm{~mA}$, and the electricity use changing accordingly.

The performance of PHOENIX with fewer than 8 target modules in place, assuming keffective is 0.9 , is illustrated in Figure 28 . Note that there is net positive electricity generated in all cases, although the proportion available to the electrical grid improves as more modules are brought on line. With fewer than eight targets loaded, a higher current can be delivered per target module. Thus, a target with a first-cycle fuel loading could be driven along using a higher beam current until the $\mathrm{k}$ increases to 0.9 . 


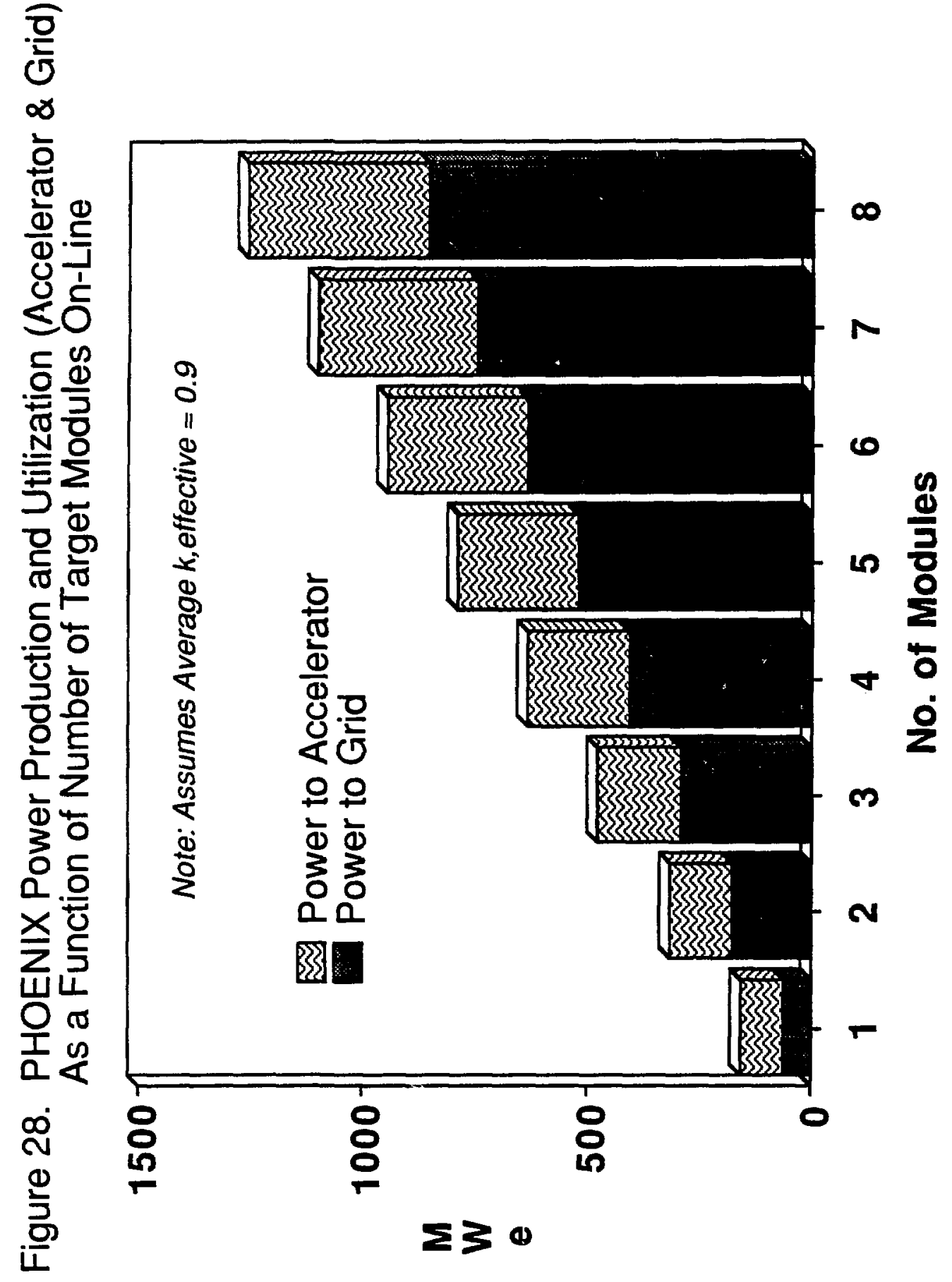




\section{IMPACT OF PHOENIX ON ACTINIDE INVENTORIES}

The large through-put of minor actinides in PHOENIX, 2.6 tonnes/year, is required to handle the LWR waste stream. The inventory of minor actinides, based on 100 operating 1000 MW $\mathrm{e}_{\mathrm{e}}$ LWRs, is projected from years 2000 through 2050 in Figure 29.

The usage of 1 PHOENIX unit starting in the year 2000 would cut the growth in the minor actinide inventory by $75 \%$. If a second unit starts up in the year 2010, all of the back-log of minor actinides would be consumed by early 2040s. (It is noted that the current average capacity factors for U.S. LWRs are below $65 \%$, so that 1 PHOENIX unit could process almost all of the current production of minor actinides.) 
Figure 29. Impact of PHOENIX on Minor Actinide Inventory if Continue Current LWRs

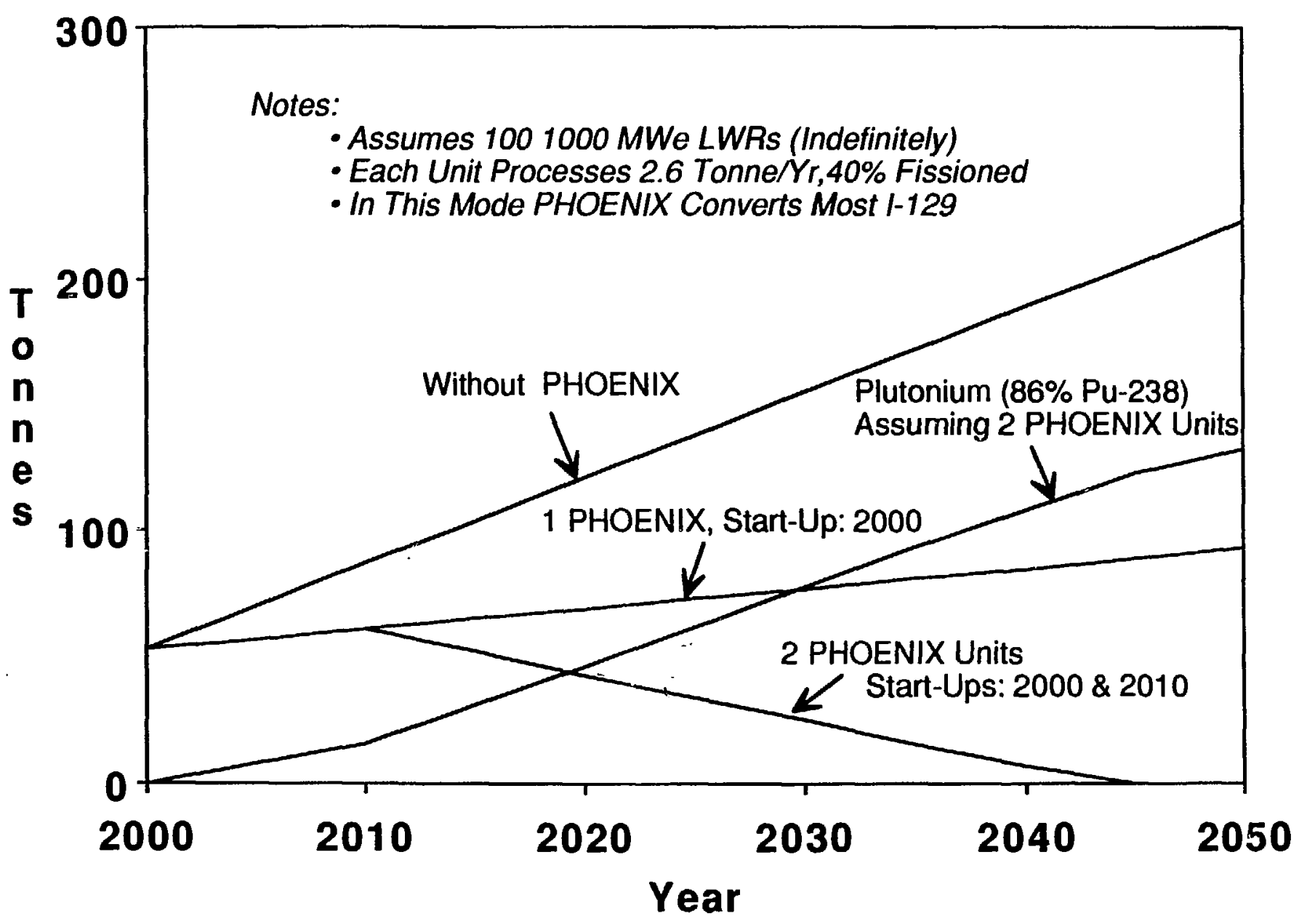




\section{ENGINEERING FEASIBILITY STUDY}

We consider the PHOENIX Concept credible as a large-scale actinide burner for transmuting nuclear wastes. The current design is based on both simplified analysis and a few more detailed physics and neutronics calculations, and is by no means finalized or optimized. The next step is to determine whether such a machine is feasible from an engineering standpoint, i.e., can such a machine be built and operated. In some instances this may involve consideration of trade-offs of various options, such as the structural materials to be used in the target. A list of the major areas to be evaluated as part of an engineering feasibility study follows:

1. Because an accelerator designed to deliver a $250 \mathrm{~mA}$ current of $1.6 \mathrm{GeV}$ has already been independently evaluated by a DOE ERAB Committee, we are adopting a down-sized version of that machine as our reference design. During this study we would evaluate cost savings that would result from eliminating the "funneling" aspect of the $250 \mathrm{~mA}$ design, and consider whether other types of accelerators might warrant consideration.

2. BNL has an operational two-dimensional beam expander system, upon which the larger beam expander required for PHOENIX would be based. The distribution of protons in both dimensions are quite similar to the proton distributions that were predicted analytically, and we believe that this system can be scaled up without major difficulties. As part of this study we would perform the necessary design calcuiations, and consider issues such as possible expander system failure modes and possible materials damage in the large scale system.

3. The major focus of the feasibility study will be the target system. Even though the current target design is based on the FFTF reactor, there are some key differences that must be considered. These differences include a somewhat harder neutronic spectrum, due to the neutrons created via spallation and evaporation, as well as the use of $\mathrm{Am}, \mathrm{Np}$, and $\mathrm{Cm}$ rather than $\mathrm{U}$ and $\mathrm{Pu}$. Also, the PHOENIX target modules will be designed for high leakage of neutrons and large burnup reactivity swings. Finally, the high energy protons will add to the materials damage, although the predominance of neutron-induced fissions suggests that the materials behavior in FFTF should provide an excellent first guess regarding materials damage. Target system efforts would include the following:

a. Using Monte-Carlo codes (HETC/NMTC and MCNP) and Neutron Transport Codes (ANISN) to perform multi-dimensional analyses of the processes taking place in the target lattices. This would entail determining three-dimensional neutron, proton, and power distributions, the neutron multiplication factor ( $k$-effective), and key reactivity feedbacks including, Doppler and sodium void worth.

b. The target dimensions must be optimized to give the desired neutron leakage. Further, the anticipated increase in reactivity must be compensated for, and some combination of poison rods and geometry changes must be planned.

c. In principle, a metal fuel form would provide a harder neutronic spectrum than that in an oxide fuel lattice and could provide improved machine efficiencies and reduced 
burnup reactivity swings. During the proposed study, we plan to perform calculations sufficient to quantify the potential advantages from using metal fuel. In addition, alternate coolant options would be evaluated.

d. Neutronic data bases are required to predict target performance and how that performance will change with burnup. BNL's cross section libraries are state-of-the art, but the data for the minor actinides in a fast neutronic spectrum may not be as complete as one would like. This situation will have to be evaluated.

e. While extrapolation from materials testing at FFTF should provide good initial estimates of the materials damage to be expected in the PHOENIX target, tests using $1.6 \mathrm{GeV}$ protons should be planned. We can access a beam of $1.6 \mathrm{GeV}$ protons from BNL's Alternating Gradient Synchrotron (AGS) Booster and, by focusing on a few square cenimeters of surface area, replicate the proton beam intensity expected at the front face of the PHOENLX Target Modules.

4. Hanford (Brager, et al, ANS Transactions, Volume 62) has recently proposed an iodine target based on $\mathrm{Ce}_{3}$ with HT-9 cladding. This fission product target design will be evaluated for use in the PHOENIX concept. Fission product target configurations will be considered, and estimates will be made regarding the rate at which I-129 can be transmuted to stable xenon isotopes.

At the end of the proposed study, we would expect to have a viable target design, estimates of the iodine throughput and materials damage, and a conceptual design for both the accelerator and beam expansion systems. 


\section{SUMMARY}

The PHOENIX Concept utilizes a large hybrid proton accelerator-subcritical lattice and power conversion system to transmute large quantities of the minor actinides and iodine produced by current generation light water reactors (LWRs). A large unit, generating a net of about $850 \mathrm{MWe}$, would transmute the minor actinides and much of the iodine from 75 operating LWRs.

The large linear accelerator would produce a beam of up to $104 \mathrm{~mA}$ of $1.6 \mathrm{GeV}$ protons. Previous accelerators have produced similar currents or similar energies, although this accelerator would be the largest in terms of high current in combination with high energy. However, an even larger $250 \mathrm{~mA}, 1.6 \mathrm{GeV}$ proton accelerator was designed for a tritium production concept, and a board of experts found that accelerator to be credible.

The PHOENIX subcritical lattice, also known as the target, is essentially eight FFTF reactor modules aligned across the front of the proton beam. The minor actinides are substituted for the uranium and plutonium in the normal FFTF oxide fuel pins. When operated slightly subcritical, i.e., $k$-effective in the range of 0.9 to 0.95 , the target physics is dominated by the fission processes, and the materials damage would be dominated by the neutron flux. Thus, the PHOENIX target modules would operate like a reactor with a large neutron source, and the importance of the protons impacting on the targets is fairly small in comparison.

While we consider the PHOENIX Concept to be credible, we believe that a modest engineering feasibility study should be undertaken to examine any potential problem areas and scope out any future work. Over the longer term, we believe that there exists a fairly substantial infrastructure in the U.S. for developing such a machine, which involves the development of a large Linac and a target system which is based on liquid metal cooled reactor technology. 


\section{REFERENCES}

1. Binney, S. E., et al., "CURE: Clean Use of Reactor Energy," Westinghouse Hanford Report WHC-EP-0268, May 1990.

2. Takahashi, H., "Actinide Transmutation by the Spallation Process," Presented at Workshop on the Feasibility of Research Program in Actinide Transmutation by Spallation Process, June 18-21, 1985, EURATOM, Ispra, Varese, Italy.

3. Mukaiyama, T., et al., "Higher Actinide Transmutation Using Higher Actinide Burner Reactors," Presented at Workshop on the P-T of Minor Actinides. Mito, Ibaraki, Japan, October 16-18, 1989.

4. Lawrence, G., et al., "Preliminary Assessment of Accelerator Production of Accelerator Production of Tritium (APT)," Los Alamos National Laboratory Draft Report, 1990.

5. Energy Research Advisory Board (ERAB), "Accelerator Production of Tritium (APT)," a Report to the U.S. Department of Energy, February 1990.

6. Westinghouse Hanford Company, "Final Safety Analysis Report for the Fast Flux Test Facility," HEDL-TI-75001, December 1975.

7. Hebel, L. C. et al,, "Report to the American Physical Society by the Study Group on Nuclear Fuel Cycles and Waste Management, " Rev. Mod. Phys., 50, I, Part II, January 1978.

8. Pigford, T. H. et al., "A Study of the Isolation System for Geologic Disposal of Radioactive Wastes," p. 269, National Academy Press, Washington, D.C., 1983.

9. Croff, A. G. et al., "A Preliminary Assessment of Partitioning and Transmutation as a Radioactive Waste Management Concept," ORNL/TM-5808, Oak Ridge National Laboratory, September 1977.

10. Croff, A, G. et al., "Actinide Partitioning-Transmutation Program Final Report. I. Overall Assessment," ORNL-5566, Oak Ridge National Laboratory, June 1980.

11. Croff, A. G. et al., "A Re-examination of the Incentives for Actinide Burnings," Transactions of the American Nuclear Society, Vol. 62, pp. 76-78, November 1990.

12. Pigford, T. H., "Reprocessing Incentives for Waste Disposal," Transactions of the American Nuclear Society, Vol. 62, pp. 97-99, November 1990.

13. Matveev, V. I. et al., "Physical Grounds for Further Improvement of Fast Sodium Power Reactor Safety," Proceedings of the 1990 International Fast Reactor Safety Meeting, August 12-16, 1990, Snowbird, Utah. 


\section{REFERENCES (CONT'D)}

14. Croff, A. G., "ORIGEN2: A Versatile Computer Code for Calculating the Nuclide Composition and Characteristics of Nuclear Materials," Nuclear Technology, Vol. 62, pp. 335-352, September 1983. 